NBSIR 79-1606

\title{
A VARIATIONAL EXPRESSION FOR THE SCATTERING MATRIX OF A COAXIAL LINE STEP DISCONTINUITY AND ITS APPLICATION TO AN OVER MODED COAXIAL TEM CELL
}

\section{Sreenivasiah}

David C. Chang

University of Colorado

Sponsored by:

Electromagnetic Fields Division

National Engıneering Laboratory

National Bureau of Standards

Boulder, Colorado 80303

May 1979 


$$
\rightarrow-\infty
$$




\section{NBSIR 79-1606}

\section{A VARIATIONAL EXPRESSION FOR THE SCATTERING MATRIX OF A COAXIAL LINE STEP DISCONTINUITY AND ITS APPLICATION TO AN OVER MODED COAXIAL TEM CELL}

I. Sreenivasiah

David C. Chang

University of Colorado

Sponsored by:

Electromagnetic Fields Division

National Engineering Laboratory

National Bureau of Standards

Boulder, Colorado 80303

May 1979

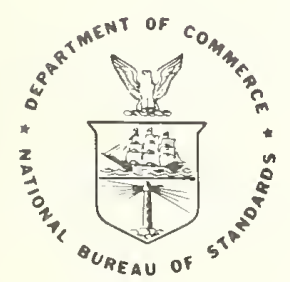

U.S. DEPARTMENT OF COMMERCE, Juanita M. Kreps, Secretary Sidney Harman, Under Secretary Jordan J. Baruch, Assistant Secretary for Science and Technology 


\section{FOREWORD}

This report describes a theoretical analysis developed by staff of the University of Colorado at Boulder under a contract sponsored by the National Bureau of Standards (NBS). Professor David C. Chang heads the University team. Mark T. Ma of the NBS Electromagnetic Fields Division serves as the current technical contract monitor. The period covered by this report extends from August 1978 to January 1979.

The work described in this report represents a further aspect of theoretical analyses of Transverse Electromagnetic (TEM) Transmission line cells developed at NBS. The purpose of this effort is to evaluate the use of TEM cells for (i) measuring the total RF radiated power by a device inserted into the cell for test, or ( $i$ ) performing necessary susceptibility tests on a small electronic device.

Previous results indicate that the useful frequency range of such TEM cells is limited by the higher-order modes that may be excited at the junction and propagate in the cell. A knowledge of the relative strengths of these higher-order modes might enable designers to extend the usable frequency range and/or to minimize the effect of these modes on the transmission characteristics of the cell.

In this report, the transition region of the cell is considered to consist of coaxial transmission lines with different cross-sectional areas. The coupling between the different modes is analyzed by a scattering-matrix formulation. An equivalent circuit is developed for the general case where the number of propagating modes in each transmission line is finite but arbitrary. A network representation for the entire cell including the transition region is also given. 
I. INTRODUCTION . . . . . . . . . . . . . . . . . . 1

II. SCATTERING MATRIX OF A STEP DISCONTINUITY IN A COAXIAL TRANSMISSION LINE . . . . . . . . . . . 5

III. EQUIVALENT CIRCUIT FOR THE GENERAL CASE . . . . . . . . . 12

IV. ANALYSIS OF AN OVER-MODED TEM CELL . . . . . . . . . . . 16

V. NUMERICAL RESULTS . . . . . . . . . . . . . . . 18

VI. CONCLUSIONS . . . . . . . . . . . . . . . . . . . 24

VII. ACKNOWLEDGMENTS . . . . . . . . . . . . . . 25

REFERENCES . . . . . . . . . . . . . . . . 25

APPENDIX I . . . . . . . . . . . . . . . 27

APPENDIX II . . . . . . . . . . . . . . . 29

APPENDIX III . . . . . . . . . . . . . . . . 33

APPENDIX IV . . . . . . . . . . . . . . . . . 35 


\section{LIST OF ILLUSTRATIONS}

Page

Figure 1. Cross-sectional views of a typical TEM cell . . . . . . . . . 2

Figure 2. Cross-sectional view of a coaxial TEM cell. . . . . . . . . 3

Figure 3. Equivalent network of a coaxial TEM cell with a small

source and loading material in place. . . . . . . . . . . . 4

Figure 4. (a) Coaxial transmission line with a step discontinuity

at $z=0 . . . . . . . . . . . . . . . .66$

(b) Representation of the discontinuity when only one

higher order mode is propagating. . . . . . . . . . . 6

Figure 5. Equivalent circuit of the discontinuity when only one

higher order mode is propagating. . . . . . . . . . . . . 13

Figure 6. Equivalent circuit of the discontinuity when arbitrary

number of higher order modes are propagating. . . . . . . . . 15

Figure 7. (a) $\mathrm{C}_{\mathrm{O}, \mathrm{N}}$ vs frequency characteristics of a step discontinuity

in a coaxial line. . . . . . . . . . . . . . . . 19

(b) $\mathrm{n}_{1}$ vs frequency characteristics of a step discontinuity

in a coaxial line. . . . . . . . . . . . . . . . 20

Figure 8. Transmission coefficient vs frequency characteristics of

an empty coaxial TEM cell. . . . . . . . . . . . . . . 21

Figure 9. Transmission coefficient vs frequency characteristics of

a coaxial TEM cell with internal resistive loading . . . . . . . 22

Figure 10. Transmission characteristics of a coaxial TEM cell

with an internal source. . . . . . . . . . . . . . . 23 
Previous publications under the same effort include:

J. C. Tippet and D. C. Chang, Radiation characteristics of dipole sources located inside a rectangular coaxial transmission line, NBSIR 75-829, January 1976.

J. C. Tippett, D. C. Chang and M. L. Crawford, An analytical and experimental determination of the cut-off frequencies of higher-order TE modes in a TEM cel1, NBSIR 76-841, June 1976.

J. C. Tippet and D. C. Chang, Higher order modes in rectangular coaxial line with infinitely thin inner conductor, NBSIR 78-873, March 1978. 
A VARIATIONAL EXPRESSION FOR THE SCATTERING MATRIX OF A COAXIAL LINE STEP DISCONTINUITY AND ITS APPLICATION TO AN OVER MODED COAXIAL TEM CELL

I. Sreenivasiah

and

David C. Chang

A step discontinuity in a coaxial transmission line, where one of the sections is large enough to support both TEM and $\mathrm{TM}_{01}$ modes, may be modeled as a 3-port junction. A variational expression for the (3x3) scattering matrix of such a junction is obtained in simple closed form. The scattering matrix, so obtained, is used to analyze the transmission characteristics of a coaxial TEM cell beyond the cutoff point of the TM mode. Finally, an equivalent circuit, along with the expressions for the circuit parameters, is given for the general case where the number of propagating modes in each section is finite but arbitrary.

Key words: Coaxial transmission line; cut-off frequency; equivalent circuit; modal analysis; scattering matrix; step discontinuity; TEM-cell; variational formulation. 


\section{I . INTRODUCTION}

Recently there has been considerable interest in developing methods for measuring the electromagnetic emissions by and/or penetration into electronic equipment [1]. Among others is a TEM cell consisting of a section of rectangular coaxial transmission line connected at both ends to $50 \Omega$ coaxial lines through tapers as shown in Fig. 1. The details of the design and evaluation of such cells are given elsewhere [2] - [5]. -The useful frequency range of such a cell is limited by the higher order modes that may be excited at the junctions and propagate inside the cell. A knowledge of the strength and the effect of these modes on the transmission characteristics of the cell might enable one to find ways to minimize such effects; for example, by placing absorbing material at selective places, or to calibrate the cell with due consideration to the propagating higher order modes. Since a taper of the type shown in Fig. 1 is difficult to analyze it was felt that a qualitative understanding may be gained by analyzing a simpler coaxial TEM cell of the type shown in Fig. 2. When the frequency is high enough that the first higher order mode TM 01 may propagate inside the cell, one can analyze the transmission characteristics of the cell by the equivalent transmission line network shown in Fig. 3 where the TEM cell is replaced by two transmission lines corresponding to the two propagating modes. These lines are coupled to the output ports through 3-port junctions which correspond to the step discontinuities in Fig. 2. It is assumed that the dimensions of the output lines are such that only the TEM mode can propagate. In Fig. 3 two voltage sources are indicated to account for the possibility of exciting the cell with a small source within the cell, which could be the radiating test object itself. The load impedances $z_{L 2}$ and $z_{L 3}$ could account for selective placement of a sheet of absorbing material to modify or suppress the resonances within the cell.

In order to analyze such a circuit, one obviously needs to develop first the scattering matrix representing the coupling between different modes in the transition 


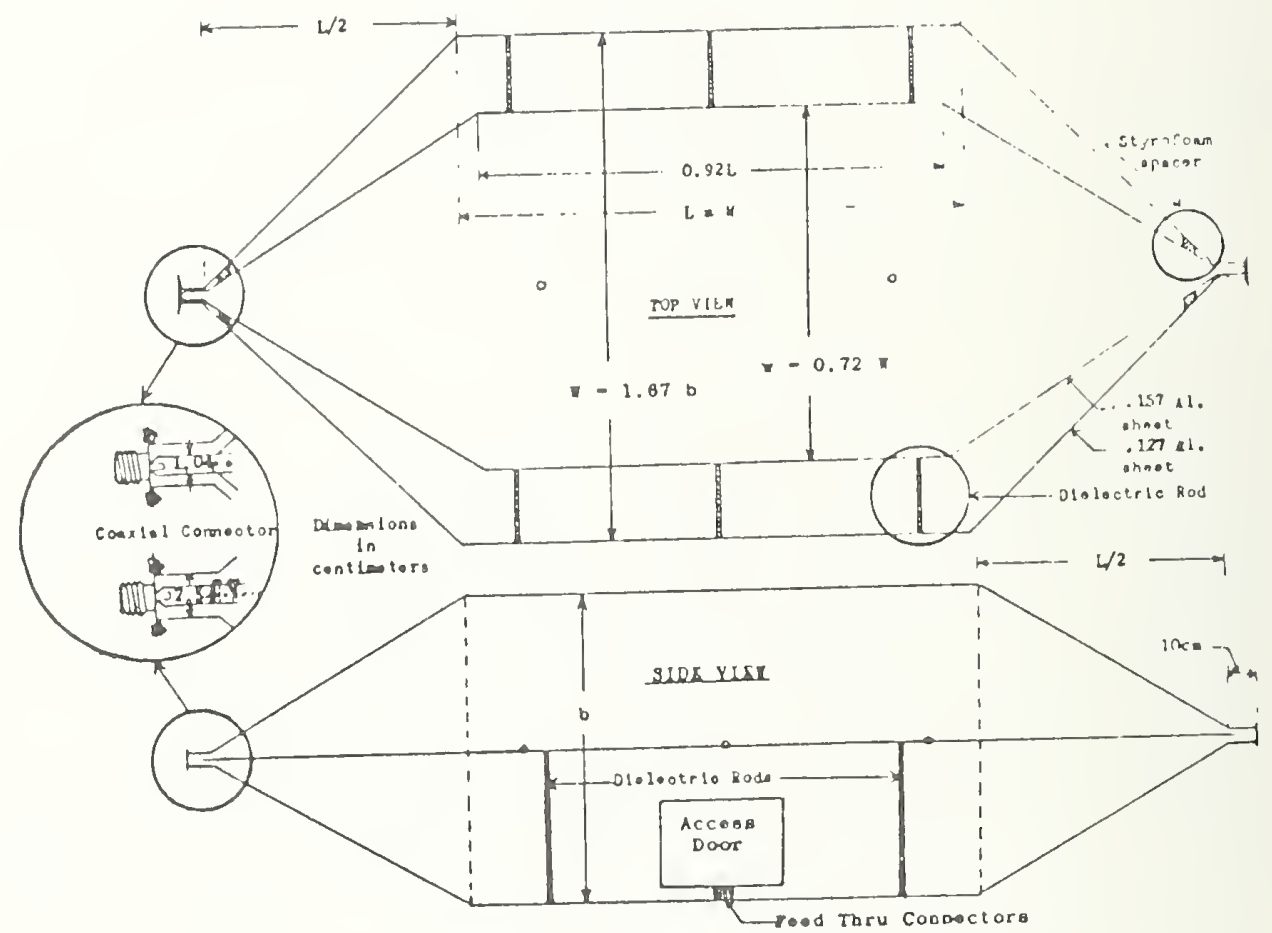

Figure 1. Cross-sectional views of a typical TEM ce11 


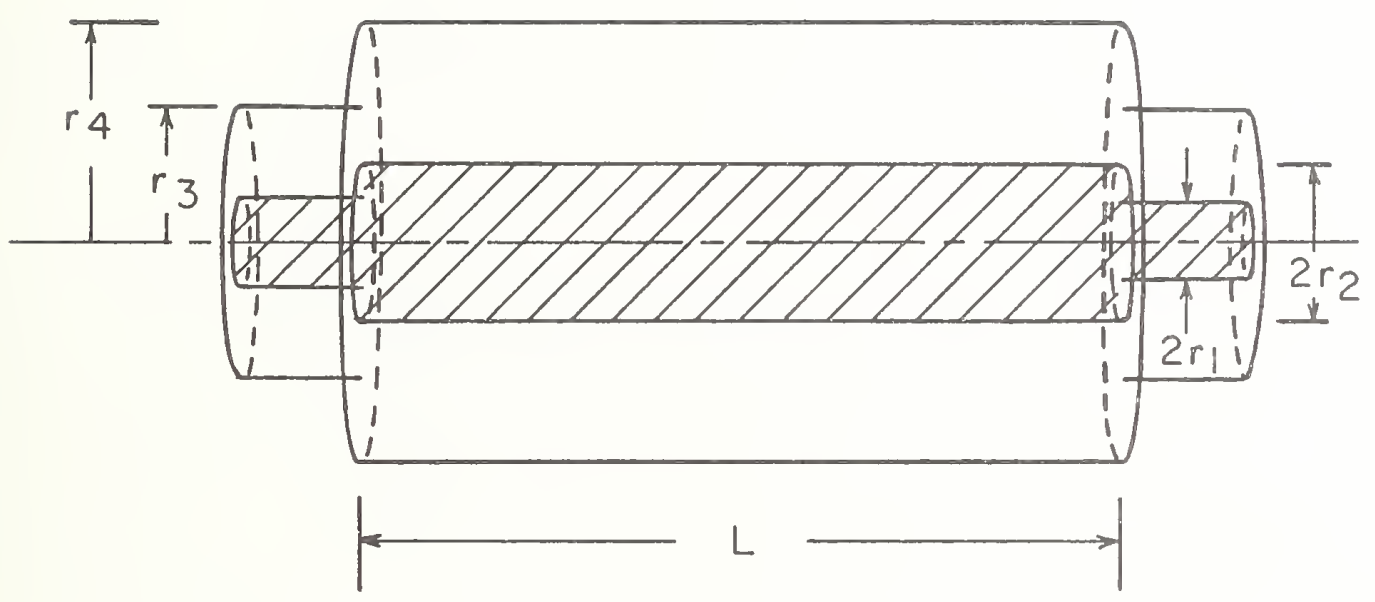

Figure 2. Cross-sectional view of a coaxial TEM cell 


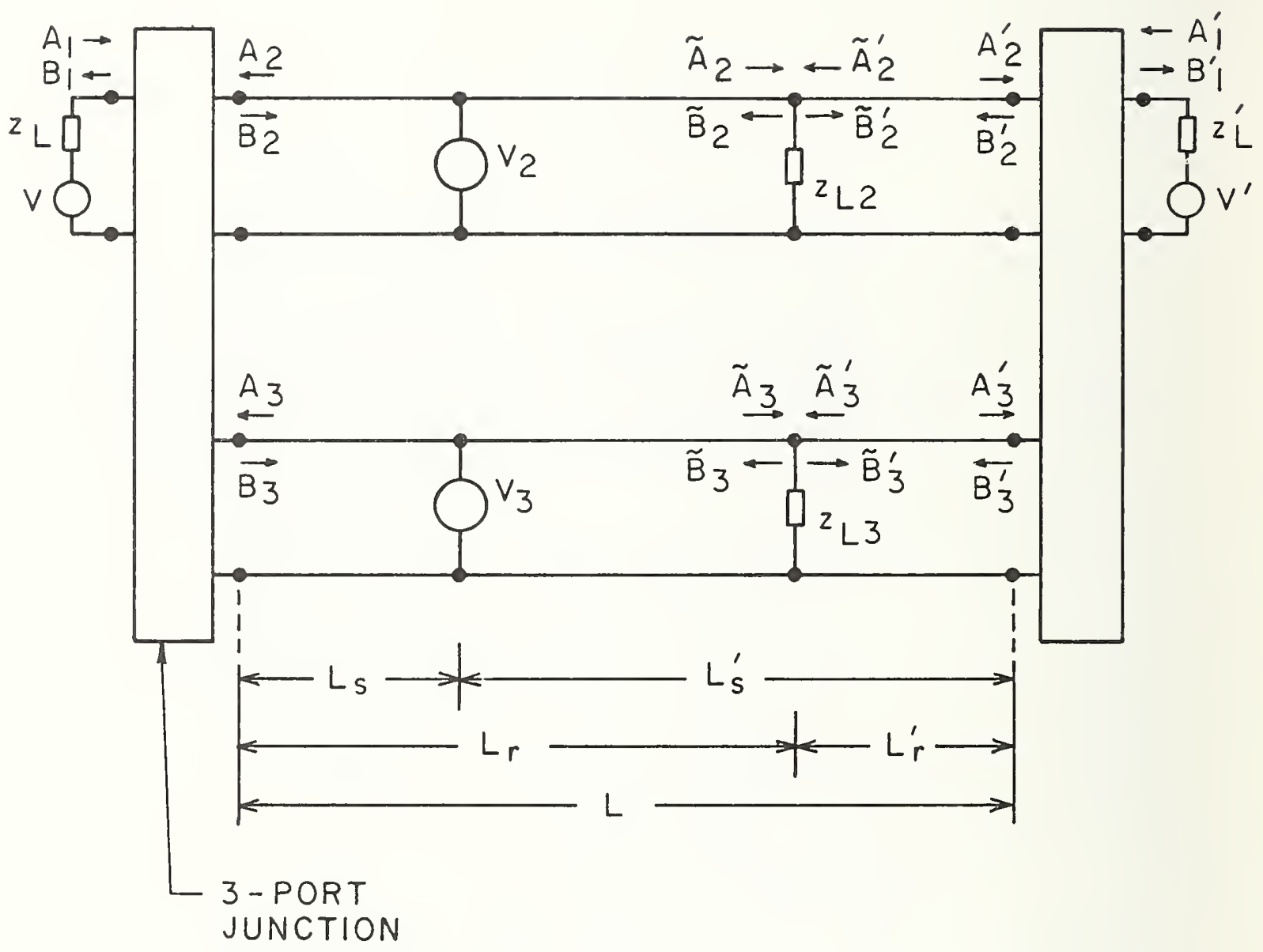

Figure 3. Equivalent network of a coaxial TEM ce11 with a small source and loading material in place 
region. In this report, a variational formulation of the scattering matrix elements is derived and later generalized to a finite but arbitrary number of propagating modes in each coaxial section. Numerical results for the transmission of TEM mode to and from a coaxial TEM cell capable of propagating TEM as well as TM 01 mode are then given.

\section{SCÄTTERING MATRIX OF A STEP \\ DISCONTINUITY IN A COAXIAL TRANSMISSION LINE}

Consider an infinitely long coaxial transmission line with a step discontinuity in the plane $z=0$ as shown in Fig. 4 (a). The radii of the inner and the outer conductors of the line are given by $r_{1}$ and $r_{3}$ for $z<0$ and $r_{2}$ and $r_{4}$ for $z>0$. The dimensions of the line and the frequency are assumed to be such that only the TEM mode can propagate in the left-hand side section $A(z \leq 0)$ and two modes, namely the TEM and the $\mathrm{TM}_{01}$, can propagate in the right-hand side $\mathrm{B}(z \geq 0)$. In such a case the discontinuity may be represented by a 3 -port junction, with a scattering matrix S, as shown in Fig. 4 (b).

A. Expression for the scattered magnetic field

Let the incident and the reflected magnetic fields $\mathrm{H}_{\phi i}^{+}$and ${\mathrm{H}_{\phi i}^{-}}^{-}, \mathrm{i}=1,2,3$, as shown in Fig. 4 (a), be given by

$$
\begin{aligned}
& \mathrm{H}_{\phi 1}^{( \pm)}(\rho, z)=\left(\begin{array}{l}
+\mathrm{a}_{1} \\
-\mathrm{b}_{1}
\end{array}\right)\left(2 \pi \zeta_{0}\right)^{-1 / 2} z_{0}\left(r_{1}, r_{3}, \rho\right) e^{(\mp) i \beta_{0}, A^{z}} \\
& H_{\phi 2}^{( \pm)}(\rho, z)=\left(\begin{array}{l}
-a_{2} \\
+b_{2}
\end{array}\right)\left(2 \pi \zeta_{0}\right)^{-1 / 2} z_{0}\left(r_{2}, r_{4} ; \rho\right) e^{( \pm) i \beta_{0}, b^{z}} \\
& \mathrm{H}_{\phi 3}^{( \pm)}(\rho, z)=\left(\mathrm{C}_{+\mathrm{b}_{3}}^{-\mathrm{a}_{3}}\right)\left(2 \pi \zeta_{0} \beta_{1, B} / \beta_{O},\right)^{-1 / 2} z_{1}\left(\mathrm{r}_{2}, \mathrm{r}_{4} ; \rho\right) \mathrm{e}^{( \pm) i \beta} 1, \mathrm{~B}^{z}
\end{aligned}
$$

where $\zeta_{0}=\sqrt{\mu / \varepsilon}$ is the characteristic impedance of the free space; $z_{p}(a, b ; \rho)$ is the orthonormal function for the magnetic field of $\mathrm{TM}_{\mathrm{op}}$ mode, $\mathrm{p}=0$ being the TEM 


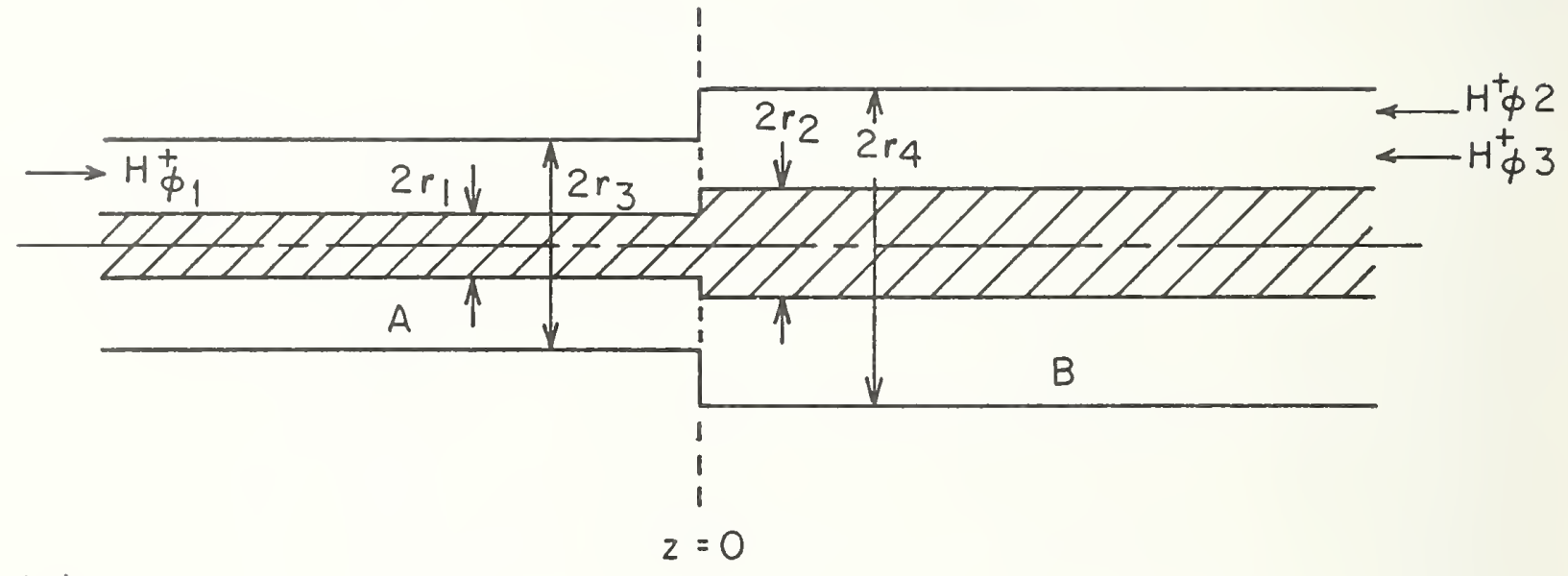

(a)

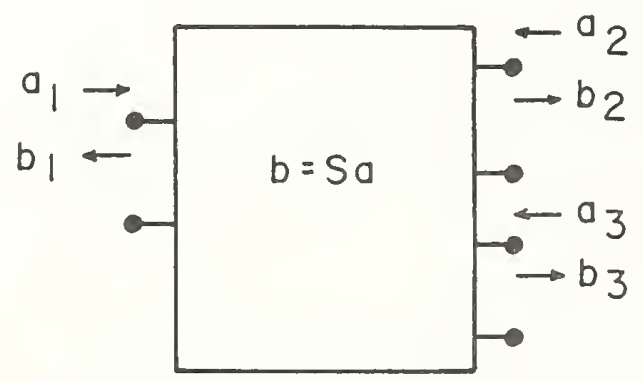

(b)

Figure 4. (a) Coaxial transmission line with a step discontinuity at $z=0$

(b) Representation of the discontinuity when only one higher order mode is propagating 
mode in a coaxial line, with inner and outer conductors of radii a and b respectively; $\beta_{p, A}$ and $\beta_{p, B}$ are the propagation constants of the $\mathrm{TM}_{\mathrm{op}}$ mode in regions $\mathrm{A}$ and $\mathrm{B}$ respectively, and a time dependence of $\exp (i \omega t)$ is assumed and suppressed. We note that the incident waves at ports 2 and 3 are incident from the right to yield a propagation factor of $\exp \left(+i \beta_{0, B} z\right)$ and $\exp \left(+i \beta_{1, B}\right)$, opposite to that of port 1 . The modal functions $z_{p}$ are given by

$$
\begin{aligned}
& Z_{p}(a, b ; \rho)= \begin{cases}1 /(f \sqrt{ } n(b / a)\} & ; p=0 \\
A_{p} \bar{z}_{p}(a, b ; \rho) & ; p \geq 1\end{cases} \\
& \bar{Z}_{p}(a, b ; \rho)=J_{1}\left(\lambda_{p} \rho\right)+B_{p} N_{1}\left(\lambda_{p} \rho\right) \\
& A_{p}=\sqrt{2}\left\{b^{2} Z_{p}^{2}\left(\lambda_{p} b\right)-a^{2} z_{p}^{2}\left(\lambda_{p} a\right)\right\}^{-1 / 2} \\
& B_{p}=-J_{0}\left(\lambda_{p} a\right) / N_{0}\left(\lambda_{p} a\right)
\end{aligned}
$$

where $J_{n}$ and $N_{n}$ represent $n{ }^{\text {th }}$ order Bessel functions of the first and the second kind and $\lambda_{p}$ are the roots of the equation

$$
J_{0}\left(\lambda_{p} a\right) N_{0}\left(\lambda_{p} b\right)-J_{0}\left(\lambda_{p} b\right) N_{0}\left(\lambda_{p} a\right)=0
$$

The propagation constants $\beta_{\mathrm{p}, \mathrm{A}}$ and $\beta_{\mathrm{p}, \mathrm{B}}$ are given by

$$
\beta_{p, A}= \begin{cases}\beta=\omega / c & ; p=0 \\ \left\{\beta^{2}-\lambda_{p}^{2}\left(r_{1}, r_{3}\right)\right\}^{1 / 2} & ; p \geq 1 ; \beta>\lambda_{p} \\ 2 & 4 \\ -i\left\{\lambda_{p}^{2}\left(r_{1}, r_{3}\right)-\beta^{2}\right\}^{1 / 2} & ; p \geq 1 ; \lambda_{p}>\beta\end{cases}
$$

We have chosen $a_{i}$ and $b_{i}$ such that $a_{i} a_{i}^{*}$ and $b_{i} b_{i}^{*}$ give the incident and the reflected powers respectively, in the $i^{\text {th }}$ port. Then the scattering matrix $S$ relates the coefficients $a_{i}$ and $b_{i}$ through

$$
b_{i}=\sum_{j=1}^{3} S_{i j} a_{j} \quad ; \quad i=1,2,3
$$


We let $\mathrm{H}_{\phi \mathrm{A}}$ and $\mathrm{H}_{\phi \mathrm{B}}$ be the total magnetic fields in regions $\mathrm{A}$ and $\mathrm{B}$ respectively and define the scattered fields $\mathrm{H}_{\phi \mathrm{A}}^{\mathrm{S}}$ and $\mathrm{H}_{\phi \mathrm{B}}^{\mathrm{S}}$ as

$$
\begin{aligned}
& \mathrm{H}_{\phi A}^{\mathrm{S}}(\rho, z)=\mathrm{H}_{\phi A}(\rho, z)-\mathrm{H}_{\phi 1}^{+}(\rho, z) \quad, z<0 \\
& \mathrm{H}_{\phi \mathrm{B}}^{\mathrm{S}}(\rho, z)=\mathrm{H}_{\phi \mathrm{B}}(\rho, z)-\mathrm{H}_{\phi 2}^{+}(\rho, z)-\mathrm{H}_{\phi 3}^{+}(\rho, z), z \geq 0
\end{aligned}
$$

Defining the transverse electric fields $E_{\rho A}, E_{\rho B}, E_{\rho A}^{S}$, and $E_{\rho B}^{S}$ in a similar manner we can obtain (Appendix I) $H_{\phi A}^{S}(\rho, z)$ and $H_{\phi B}^{S}(\rho, z)$ in terms of $E_{\rho A}^{S}$ and $E_{\rho B}^{S}$ as

$$
\begin{aligned}
& \mathrm{H}_{\phi \mathrm{A}, \mathrm{B}}^{\mathrm{S}}=\mp \omega \varepsilon \int_{\mathrm{r}_{1,2}}^{\mathrm{r}_{3,4}} \mathrm{E}_{\rho \mathrm{A}, \mathrm{B}}^{\mathrm{S}}\left(\rho^{\prime}, 0\right) \rho^{\prime} \mathrm{d} \rho^{\prime} \sum_{\mathrm{p}=0}^{\infty} \Sigma_{\mathrm{p}}\left(\mathrm{r}_{1,2}, \mathrm{r}_{3,4} ; \rho\right) z_{\mathrm{p}}\left(\mathrm{r}_{1,2}, \mathrm{r}_{3,4} ; \rho^{\prime}\right)\left(\beta_{\mathrm{p}, \mathrm{A}}\right)^{-1} \\
& \exp \left(+\underset{p, \beta_{B}}{z}\right)
\end{aligned}
$$

B. Scattering matrix of a 3-port junction

In view of equations $(2.1 \mathrm{a}-\mathrm{c})$ we identify the coefficients $b_{1}, b_{2}$, and $b_{3}$ from $(2.6)$ to be

$$
\begin{aligned}
& b_{1,2}=\frac{1}{z_{1,2}^{1 / 2}} \int_{r_{1,2}}^{r_{3}, 4} E_{\rho A, B}^{s}\left(\rho^{\prime}, 0\right) \mathrm{d} \rho^{\prime} \\
& b_{3}=\left(\frac{2 \pi \beta}{\zeta_{0} \beta_{1, B}}\right)^{1 / 2} \int_{r_{2}}^{r_{4}} E_{F}^{s}\left(\rho^{\prime}, 0\right) H_{1}\left(\rho^{\prime}\right) \rho^{\prime} \mathrm{d} \rho^{\prime}
\end{aligned}
$$

where

$$
\begin{aligned}
& z_{1}=\left(\zeta_{0} / 2 \pi\right) \ln \left(r_{3} / r_{1}\right) \\
& z_{2}=\left(\zeta_{0} / 2 \pi\right) \ln \left(r_{4} / r_{2}\right)
\end{aligned}
$$

Further, by noting that

$$
E_{\rho A}(\rho, z)=E_{\rho A}^{S}(\rho, z)+E_{\rho 1}^{+}(\rho, z) \quad ; \quad z<0
$$

and

$$
E_{\rho B}(\rho, z)=E_{\rho B}^{S}(\rho, z)+E_{\rho 2}^{+}(\rho, z)+E_{\rho 3}^{+}(\rho, z) ; \quad z \geq 0
$$


we may write

$$
\int_{r_{1,2}}^{r_{3,4}} E_{\rho A, B}^{s}\left(\rho^{\prime}, 0\right) d \rho^{\prime}=\int_{r_{2}}^{r_{3}} E_{\rho A, B}\left(\rho^{\prime}, 0\right) d \rho^{\prime}-a_{1,2}\left(z_{1,2}\right)^{1 / 2}
$$

which, upon the use of the boundary condition

$$
\begin{gathered}
\mathrm{E}_{\rho \mathrm{A}}(\rho, 0)=\mathrm{E}_{\rho \mathrm{B}}(\rho, 0)=0 \text { for } \mathrm{r}_{1}<\rho<\mathrm{r}_{2} \text { and } \mathrm{r}_{3}<\rho<\mathrm{r}_{4} \\
\mathrm{E}_{\rho \mathrm{A}}(\rho, 0)=\mathrm{E}_{\rho \mathrm{B}}(\rho, 0)
\end{gathered}
$$

yields

$$
\left\{\mathrm{S}_{12} \mathrm{a}_{1}+\left(1+\mathrm{S}_{22}\right) \mathrm{a}_{2}+\mathrm{S}_{23} \mathrm{a}_{3}\right\}=\mathrm{n}_{\mathrm{o}}\left[\left(1+\mathrm{S}_{11}\right) \mathrm{a}_{1}+\mathrm{S}_{12} \mathrm{a}_{2}+\mathrm{S}_{13} \mathrm{a}_{3}\right]
$$

where

$$
n_{0}=\left(z_{1} / z_{2}\right)^{1 / 2}
$$

for arbitrary values of $a_{1}, a_{2}$, and $a_{3}$.

In obtaining (2.13) use has been made of (2.4) and the symmetry property of the scattering matrix of a reciprocal junction

$$
S=\tilde{S}
$$

where $\tilde{S}$ is the transpose of $\mathrm{S}$. Now, setting $\mathrm{a}_{2}=\mathrm{a}_{3}=0 ; \quad \mathrm{a}_{1}=\mathrm{a}_{3}=0 ; \mathrm{a}_{1}=\mathrm{a}_{2}=0$ consecutively enables us to obtain the following three relations among the coefficients of S:

$$
\begin{aligned}
1+\mathrm{S}_{11} & =\mathrm{s}_{12} / \mathrm{n}_{0} \\
1+\mathrm{s}_{22} & =\mathrm{n}_{0} \mathrm{~s}_{12} \\
\mathrm{~S}_{23} & =\mathrm{n}_{\mathrm{o}} \mathrm{s}_{13}
\end{aligned}
$$

Further, for a lossless junction the scattering matrix is unitary,

$$
\mathrm{S}^{-1}=\tilde{\mathrm{S}}^{*}
$$

Combining (2.16) with (2.14) we can write

$$
\mathrm{SS}^{*}=\mathrm{I}
$$

where I is an identity matrix. The above identity provides the following relations 
that are independent of the equations $(2.15 \mathrm{a}-\mathrm{c})$.

$$
\begin{aligned}
& S_{11} S_{11}^{*}+S_{12} S_{12}^{*}+S_{13} S_{13}^{*}=1 \\
& S_{11} S_{13}^{*}+S_{12} S_{23}^{*}+S_{13} S_{33}^{*}=0
\end{aligned}
$$

To determine S uniquely we therefore only need two additional relations as derived in Appendix II:

$$
\begin{aligned}
& \left\{2 n_{0}-\left(1+n_{0}^{2}\right) S_{12}\right\} / S_{12}=\beta \ell n\left(r_{3} / r_{1}\right)\left\{\sum_{p=1}^{\infty}\left(\int_{r_{2}}^{r_{3}} \sum_{\rho}^{\sim}(\rho, 0) z_{p}\left(r_{1}, r_{3} ; \rho\right) \rho d \rho\right)^{2} / \beta p, A\right. \\
& \left.+p=1\left(\sum_{r_{2}}^{r_{3}} \tilde{E}_{\rho}(\rho, 0) z_{p}\left(r_{2}, r_{4} ; \rho\right) \rho d \rho\right)^{2} / \beta_{p, B}\right\} /\left(\int_{r_{2}}^{r_{3}} \tilde{E}_{\rho}(\rho, 0) d \rho\right)^{2} \\
& \left\{\left(1-\mathrm{S}_{33}\right)\left(1-\mathrm{S}_{11}-\mathrm{n}_{\mathrm{o}} \mathrm{S}_{12}\right)-\left(1+\mathrm{n}_{\mathrm{o}}^{2}\right) \mathrm{S}_{13} \mathrm{~S}_{13}\right\} /\left\{\left(1+\mathrm{S}_{11}\right)\left(1-\mathrm{S}_{33}\right)+\mathrm{S}_{13} \mathrm{~S}_{13}\right\} \\
& =\beta \ln \left(r_{3} / r_{1}\right)\left\{\sum_{p=1}^{\infty}\left(\int_{r_{2}}^{r_{3}} \tilde{E}_{\rho}(\rho, 0) z_{p}\left(r_{1}, r_{3} ; \rho\right) \rho d \rho\right)^{2} / \beta_{p, A}\right. \\
& \left.+\sum_{p=2}^{\infty}\left(\int_{r_{2}}^{r_{3}}{ }_{\tilde{\tilde{E}}}(\rho, 0) z_{p}\left(r_{2}, r_{4} ; \rho\right) \rho d \rho\right)^{2} / \beta_{p, B}\right\} /\left(\int_{r_{2}}^{r_{3}} \tilde{\tilde{E}}_{\rho}(\rho, 0) d \rho\right)^{2}
\end{aligned}
$$

where $\tilde{\mathrm{E}}_{\rho}(\rho, 0)$ and $\tilde{\mathrm{E}}_{\rho}(\rho, 0)$ are the total transverse electric fields in the plane $z=0$ corresponding to the cases i) $a_{1}=a_{2}=1, a_{3}=0$ and $\left.i i\right) a_{1}=\left(1-S_{33}\right) / S_{13}$, $\mathrm{a}_{2}=0, \mathrm{a}_{3}=1$ respectively. The above relations $(2.19 \mathrm{a}, \mathrm{b})$ are exact, although they involve the unknown fields $\tilde{\mathrm{E}}_{\rho}(\rho, 0)$ and $\tilde{\mathrm{E}}_{\rho}(\rho, 0)$. However, as shown in Appendix II, these relations are variational with respect to the electric field distribution, which means that the right-hand side expressions are stationary for small variations in the electric field distribution from its correct value. It therefore follows that a first-order approximation to the electric field distribution will yield a second-order approximation to the desired quantities on the left-hand sides of these relations. Further, the expressions on the right-hand sides are homogeneous in the sense that they do not depend on the amplitude of the electric field distribution but only on its functional form. In view of this, we can use the following first- 
order approximations

$$
\begin{aligned}
& \tilde{\mathrm{E}}_{\rho}(\rho, 0) \doteq \mathrm{C}_{1} / \rho \\
& \tilde{\tilde{\mathrm{E}}}_{\rho}(\rho, 0) \doteq \mathrm{C}_{2} / \rho
\end{aligned}
$$

where the constants $\mathrm{C}_{1}$ and $\mathrm{C}_{2}$ need not be known. For small discontinuities, we note that in case i) the incident fields are completely that of the TEM mode and in case $i i)$ the amplitude $\left(1-S_{33}\right) / S_{13}$ of the TEM mode in the incident fields relative to the incident $\mathrm{TM}_{01}$ mode is quite large since $\mathrm{S}_{33}$ is close to -1 and $\mathrm{S}_{13}$ is quite small compared to unity. Hence the above approximation, where the electric field distribution is assumed to have a functional form corresponding to the TEM mode, is indeed quite reasonable. Upon substituting (2.20a and b) in (2.19a and b) respectively, we obtain

$$
\begin{gathered}
\left\{2 n_{0}-\left(1+n_{0}^{2}\right) S_{12}\right\} / S_{12}=n_{1}^{2}+i / x_{0,1} \\
\left\{\left(1-S_{33}\right)\left(1-S_{11}-n_{0} S_{12}\right)-\left(1+n_{0}^{2}\right) S_{13} S_{13}\right\} /\left\{\left(1+S_{11}\right)\left(1-S_{33}\right)+S_{13} S_{13}\right\}=i / x_{0,1}
\end{gathered}
$$

where

$$
\left.n_{1}=\left(\beta / \beta_{1, B}\right)^{\frac{1}{2}} \ln \left(r_{3} / r_{1}\right)\right)^{1 / 2}\left(\ln \left(r_{3} / r_{2}\right)\right)^{-1} \int_{r_{2}}^{r_{3}} z_{1}\left(r_{2}, r_{4} ; \rho\right) d \rho
$$

and $\quad x_{0,1}=\frac{\left(\ln \left(r_{3} / r_{2}\right)\right)^{2}}{\beta \ln \left(r_{3} / r_{1}\right)}\left\{\sum_{p=1}^{\infty}\left(\int_{r_{2}}^{r_{3}} z_{p}\left(r_{1}, r_{3} ; \rho\right) d \rho\right)^{2} / i \beta_{p, A}\right)$

$$
\left.+\sum_{=2}^{\infty}\left(\int_{r_{2}}^{r_{3}} z_{p}\left(r_{2}, r_{4} ; \rho\right) d \rho\right)^{2} /(i \beta p, B)\right\}
$$

To determine all the elements of the scattering matrix we first substitute the value of $\mathrm{S}_{12}$ obtained from (2.21a) into (2.15a and b), and obtain $\mathrm{S}_{11}$ and $\mathrm{S}_{22}$. The magnitude of $\mathrm{S}_{13}$ may then be established through (2.18a). Substituting the values of $\mathrm{S}_{11}$ and $\mathrm{S}_{12}$ in $(2.21 \mathrm{~b})$ we can write an expression for $\mathrm{S}_{33}$ in terms of $\mathrm{S}_{13}$ which, when substituted in (2.18b), along with (2.15c), determines $\mathrm{S}_{13}$ uniquely. Thus, all the elements of the scattering matrix can be determined and the final result is 
$S=\frac{-1}{\Delta}\left[\begin{array}{ccc}1+i\left(1-n_{0}^{2}-n_{1}^{2}\right) x_{0,1} & i 2 n_{0} x_{0,1} & i 2 n_{1} x_{0,1} \\ i 2 n_{0} x_{0,1} & 1-i\left(1-n_{0}^{2}+n_{1}^{2}\right) x_{0,1} & i 2 n_{0} n_{1} x_{0,1} \\ i 2 n_{1} x_{0,1} & i 2 n_{0} n_{1} x_{0,1} & 1-i\left(1+n_{0}^{2}-n_{1}^{2}\right) x_{0,1}\end{array}\right]$

$$
\Delta=1-i\left(1+n_{0}^{2}+n_{1}^{2}\right) x_{0,1}
$$

and the subscripts on $\mathrm{X}$ indicate the number of higher order modes that can propagate in the $1 \mathrm{eft}$ - and the right-hand sections of the transmission line.

It can be easily verified that the scattering matrix as given by (2.23a and b) is exactly the same as that one obtains from the equivalent circuit shown in Fig. 5, where all the 3-ports are assumed to have the same characteristic impedance of $z_{1}$. To verify this we note that the impedance matrix $z$ of the equivalent circuit shown in Fig. 5 is given by

$$
z=-\left[\begin{array}{ccc}
\operatorname{ix}_{0,1} & \operatorname{in}_{0} x_{0,1} & \text { in } x_{0,1} \\
\operatorname{in}_{0} x_{0,1} & \operatorname{in}_{0}^{2} x_{0,1} & \text { in } n_{0} x_{0,1} \\
\operatorname{in}_{1} x_{0,1} & \operatorname{in}_{0} x_{0,1} x_{0,1} & \operatorname{in}_{1}^{2} x_{0,1}
\end{array}\right]
$$

and the scattering matrix is related to $\mathrm{Z}$ through

$$
S=(Z-I)(Z+I)^{-1}
$$

\section{I . EQUIVALENT CIRCUIT FOR THE GENERAL CASE}

In Section II we have shown that the equivalent circuit of a step discontinuity, in a coaxial transmission line, with one mode propagating on one side and two modes propagating on the other side, is as shown in Fig. 5 where the parameters $n_{0}, n_{1}$, $x_{0,1}$ are given by $(2.13 b),(2.22 a)$, and $(2.22 b)$ respectively. The reactance $x_{0,1}$ 


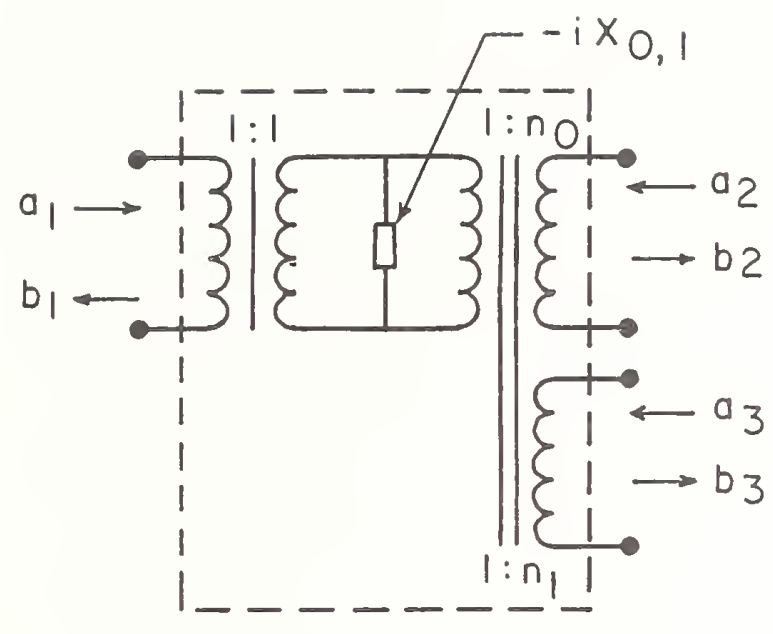

Figure 5. Equivalent circuit of the discontinuity when only one higher order mode is propagating 
and the turns ratios $\mathrm{n}_{0}$ and $\mathrm{n}_{1}$ of the transformers in the equivalent circuit determine the amount of power coupled into different modes. From the expression (2.22b) for $x_{0,1}$ we notice that the term containing $z_{1}\left(r_{2}, r_{4} ; \rho\right)$ is missing from the infinite sum. As more numbers of higher order modes start propagating in either section of the transmission line, the corresponding terms will not appear in $x$. This allows us to represent the junction when arbitrary number of modes are propagating by the general equivalent circuit shown in Fig. 6, where the circuit papameters are given by

$$
\begin{aligned}
& X_{M, N}=\frac{\left(\ln \frac{r_{3}}{r_{2}}\right)^{2}}{\beta \ell n \frac{r_{3}}{r_{1}}}\left\{\sum_{p=M+1}^{\infty}\left(\int_{r_{2}}^{r_{2}} z_{p}\left(r_{1}, r_{3} ; \rho\right) d \rho\right)^{2} /\left(i \beta_{p, A}\right)\right. \\
& \left.+\sum_{\mathrm{q}=\mathrm{N}+1}^{\infty}\left(\int_{\mathrm{r}_{2}}^{\mathrm{r}_{2}} \mathrm{z}_{\mathrm{q}}\left(\mathrm{r}_{2}, \mathrm{r}_{4} ; \rho\right) \mathrm{d} \rho\right)^{2} /(\mathrm{i} \beta \mathrm{p}, \mathrm{B})\right\}^{-1} \\
& \mathrm{n}_{\mathrm{o}}=\left(\ln \frac{\mathrm{r}_{3}}{\mathrm{r}_{1}}\right)^{1 / 2} /\left(\ln \frac{\mathrm{r}_{4}}{\mathrm{r}_{2}}\right)^{1 / 2} \\
& \mathrm{n}_{\mathrm{q}}=\left(\beta / \beta_{\mathrm{q}, \mathrm{B}}\right)^{1 / 2}\left(\ln \frac{\mathrm{r}_{3}}{\mathrm{r}_{1}}\right)^{1 / 2}\left(\ln \frac{\mathrm{r}_{3}}{\mathrm{r}_{2}}\right)^{-1} \int_{\mathrm{r}_{2}}^{\mathrm{r}_{3}} \mathrm{z}_{\mathrm{q}}\left(\mathrm{r}_{2}, \mathrm{r}_{4} ; \rho\right) \mathrm{d} \rho ; \mathrm{q}=1,2, \ldots \mathrm{N} \\
& m_{p}=\left(\beta / \beta_{p, A}\right)^{1 / 2}\left(\ln \frac{r_{3}}{r_{1}}\right)^{1 / 2}\left(\ln \frac{r_{3}}{r_{2}}\right)^{-1} \int_{r_{2}}^{r_{3}} z_{p}\left(r_{1}, r_{3} ; \rho\right) d \rho ; p=1,2, \ldots M
\end{aligned}
$$

It is straightforward to write down the impedance matrix of the equivalent circuit shown in Fig. 6 , and the corresponding $\{(M+N+2) X(M+N+2)\}$ scattering matrix may be obtained through the relation (2.25). The size of the matrix gets bigger as the frequency is increased, allowing more and more numbers of higher order modes to propagate. As we decrease the frequency, the transmission lines corresponding to the modes under cutoff will be replaced by equivalent shunt reactances which manifest themselves as additional terms in the series (3.1) for $X_{M, N}$ and when the frequency is low enough that only the TEM mode can propagate, the (2X2) scattering matrix will be entirely determined by $x_{0,0}$ and $n_{0}$. Further, we note that our expression for the discontinuity capacitance, as given by $C_{d}=1 /\left(\omega X_{0,0} z_{1}\right)$ reduces 


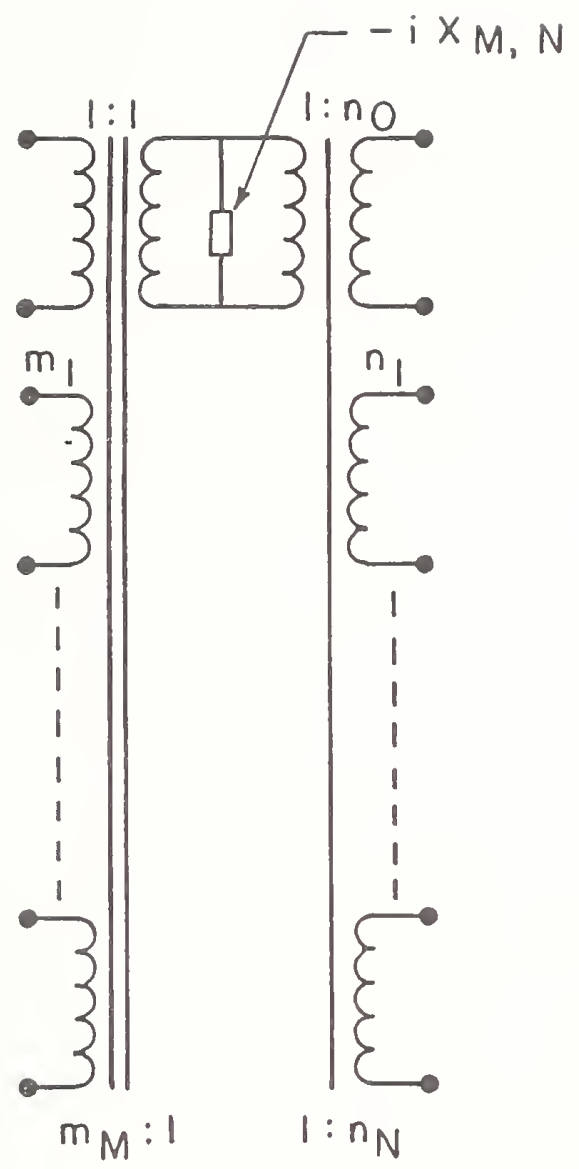

Figure 6. Equivalent circuit of the discontinuity when arbitrary number of higher modes are propagating 
to the special result derived by the others $[6,7]$ for the case when $r_{3}=r_{4}$.

\section{ANALYSIS OF AN OVER-MODED TEM CELL}

As we noted in the introduction to this paper, the characteristics of the coaxial TEM cell may be analyzed, with the knowledge of the scattering matrix of the junction, through the equivalent transmission line network shown in Fig. 3, where all the transmission lines are assumed to have a characteristic impedance of $z_{1}$. In Fig. 3,V and $V^{\prime}$ represent the external sources with internal impedances ${ }_{L}{ }$ and $z_{L}{ }^{\prime}$ respectively. In actual practice of test measurements, one or more of these sources are replaced by detectors or terminations. in which case $z_{L}$ and $z_{L}{ }^{\prime}$ represent the internal impedances or load impedances, depending on the situation. We assume that $z_{L}, z_{L}{ }^{\prime},{ }_{L}$, and $z_{L 3}$ represent the normalized impedances with respect to $z_{1}$.

Denoting $A_{i}, B_{i}, A_{i}{ }^{\prime}$, and $B_{i}{ }^{\prime}(i=1,2,3)$ to be the voltage amplitudes corresponding to the incident and the scattered power coefficients; viz. $A_{i}=a_{i} \sqrt{z_{1}}$, etc., we derive the following relations in Appendix IV:

$$
\begin{aligned}
& \overline{\mathrm{A}}=\left[\mathrm{P}_{11} \mathrm{P}_{22}-\mathrm{P}_{12} \mathrm{P}_{21}\right]^{-1}\left[\mathrm{P}_{22} \overline{\mathrm{V}}-\mathrm{P}_{12} \overline{\mathrm{V}}^{\prime}\right] \\
& \overline{\mathrm{A}}^{\prime}=\left[\mathrm{P}_{11} \mathrm{P}_{22}-\mathrm{P}_{21} \mathrm{P}_{12}\right]^{-1}\left[\mathrm{P}_{11} \overline{\mathrm{V}}^{\prime}-\mathrm{P}_{21} \overline{\mathrm{V}}\right]
\end{aligned}
$$

where

$$
\begin{aligned}
& \bar{A}=\left[A_{1} A_{2} A_{3}\right]^{T} \\
& \bar{A}^{\prime}=\left[A_{1}{ }^{\prime} A_{2}^{\prime} A_{3}^{\prime}\right]^{T} \\
& P_{11}=I-\bar{R} S \\
& P_{12}=P_{21}=-\bar{T} S \\
& P_{22}=I-\bar{R} \cdot S
\end{aligned}
$$

$\bar{R}=\left[\begin{array}{ccc}R_{c} & 0 & 0 \\ 0 & R_{c 2} e^{-i 2 \beta_{0} L_{r}} & 0 \\ 0 & 0 & R_{c 3} e^{-i 2 \beta} L_{r}\end{array}\right]$ 


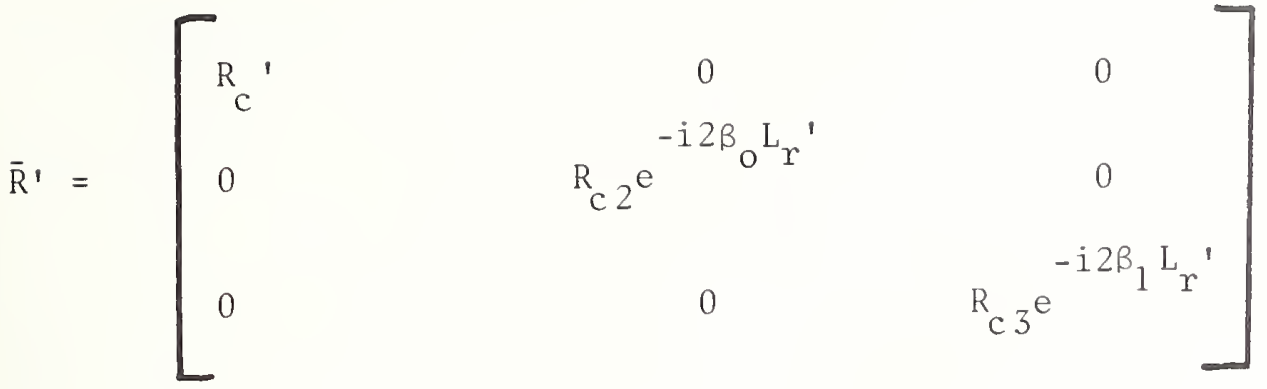

$$
\begin{aligned}
& \overrightarrow{\mathrm{T}}=\left[\begin{array}{ccc}
0 & 0 & 0 \\
0 & \mathrm{~T}_{\mathrm{c} 2} \mathrm{e}^{-i \beta_{\mathrm{O}} \mathrm{L}} & 0 \\
0 & -\mathrm{T}_{c 3} & \mathrm{~T}^{-\mathrm{i} \beta_{1} \mathrm{~L}}
\end{array}\right]
\end{aligned}
$$

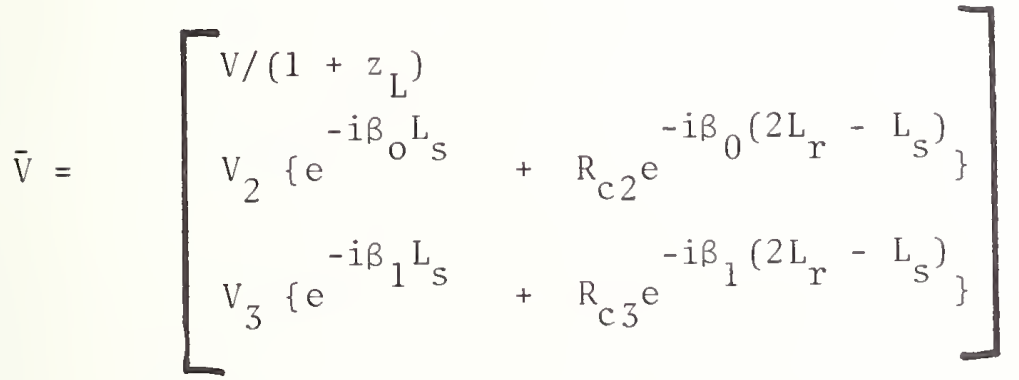

$$
\begin{aligned}
& \bar{V}^{\prime}=\left[\begin{array}{c}
V^{\prime} /\left(L+z_{L^{\prime}}{ }^{\prime}\right. \\
V_{2} T_{c 2} e^{-i \beta_{O} L_{s}^{\prime}} \\
V_{3} T_{c 3} e^{-i \beta} L_{S^{\prime}}^{\prime}
\end{array}\right] \\
& R_{C}=\left(z_{L}-1\right) /\left(z_{L}+1\right) \\
& \left.R_{C}{ }^{\prime}=\left(z_{L^{\prime}}{ }^{\prime}-1\right) / z_{L}^{\prime}+1\right) \\
& \mathrm{R}_{\mathrm{c} 2}=-1 /\left(1+2 \mathrm{z}_{\mathrm{L} 2}\right) \\
& \mathrm{T}_{\mathrm{C} 2}=\underset{3}{\mathrm{z}_{\mathrm{L} 2}} \mathrm{3}\left(1+2 \mathrm{z}_{\mathrm{L} 2}\right) \\
& \beta_{1}=\beta_{1, A} \\
& \beta_{0}=\beta=\omega / c,
\end{aligned}
$$

with $\mathrm{L}_{\mathrm{r}}, \mathrm{L}_{\mathrm{r}}^{\prime}, \mathrm{L}_{\mathrm{s}}, \mathrm{L}_{\mathrm{s}}^{\prime}$ and $\mathrm{L}$ shown in Fig. 3 . 
Once $\bar{A}$ and $\bar{A}^{\prime}$ are known, $\bar{B}$ and $\bar{B}$ ' may be readily found through the relations

$$
\begin{aligned}
& \overline{\mathrm{B}}=\left[\begin{array}{lll}
\mathrm{B}_{1} & \mathrm{~B}_{2} & \mathrm{~B}_{3}
\end{array}\right]^{\mathrm{T}}=\mathrm{S} \overline{\mathrm{A}} \\
& \overline{\mathrm{B}}^{\prime}=\left[\begin{array}{lll}
\mathrm{B}_{1}^{\prime} & \mathrm{B}_{2}^{\prime} & \mathrm{B}_{3}^{\prime}
\end{array}\right]^{\mathrm{T}}=\mathrm{S} \overline{\mathrm{A}}^{\prime}
\end{aligned}
$$

and the transmission characteristics of the cell may be completely determined.

\section{NUMERICAL RESULTS}

Using the result obtained in Section II, we have plotted the discontinuity capacitance $\mathrm{C}_{0, N}=1 /\left(50 \mathrm{X}_{0, N^{\omega}}\right)$ as a function of frequency in Fig. 7 , with the ratio $\nu=\left(r_{3}-r_{2}\right) /\left(r_{4}-r_{2}\right)$ as the parameter, choosing the ratios $r_{3} / r_{1}$ and $r_{4} / r_{2}$ to be equal and such that the characteristic impedance is $50 \Omega$ on both sides of the coaxial line. The results on the analysis of a coaxial TEM cell with dimensions $\mathrm{r}_{4}=1.0 \mathrm{~m}, \mathrm{r}_{3}=0.80 \mathrm{~m}, \mathrm{r}_{4} / \mathrm{r}_{2}=\mathrm{r}_{3} / \mathrm{r}_{3}=2.3$ are shown in Figures 8 through 10. Fig. 8 shows the voltage transmission coefficient, $\left|\beta_{1}^{\prime} / A_{1}\right|$ with $z_{L}^{\prime}=1$, of an empty cell as a function of frequency with the length $\mathrm{L}$ as a parameter. The nul1 at $263 \mathrm{MHz}$ corresponds to the cutoff point of the ${ }^{\mathrm{TM}} 01$ mode. We observe deep nulls in the neighborhood of points where the parameter $\beta_{1} L$ is an integral multiple of $\pi$. For example, the null at about $296.5 \mathrm{MHz}$ for the case where $\mathrm{L}=2.0 \mathrm{~m}$ corresponds to $\beta_{1} L=2 \pi$, and $B_{1} L=\pi$ corresponds to a frequency of 273 MHz, where we notice a shallow null. The effect of placing loading resistors is shown in Fig. 9, where the length of the cell is taken to be $2.0 \mathrm{~m}$ and resistors of normalized values $z_{\mathrm{L} 2}=10$ and $z_{\mathrm{L} 3}=1.0$ are assumed to be connected at a distance of $1.5 \mathrm{~m}$ from the source end. As anticipated, the overall insertion loss is increased with a filling of the deep nulls. However, the shallow null at the first resonance frequency has not been affected.

In Fig. 10 we have shown the results corresponding to a small dipole source midway between the cell. In this figure the magnitude of the output voltage, $\left|V_{0}\right|$, normalized with respect to an arbitrary constant, is plotted against frequency. 


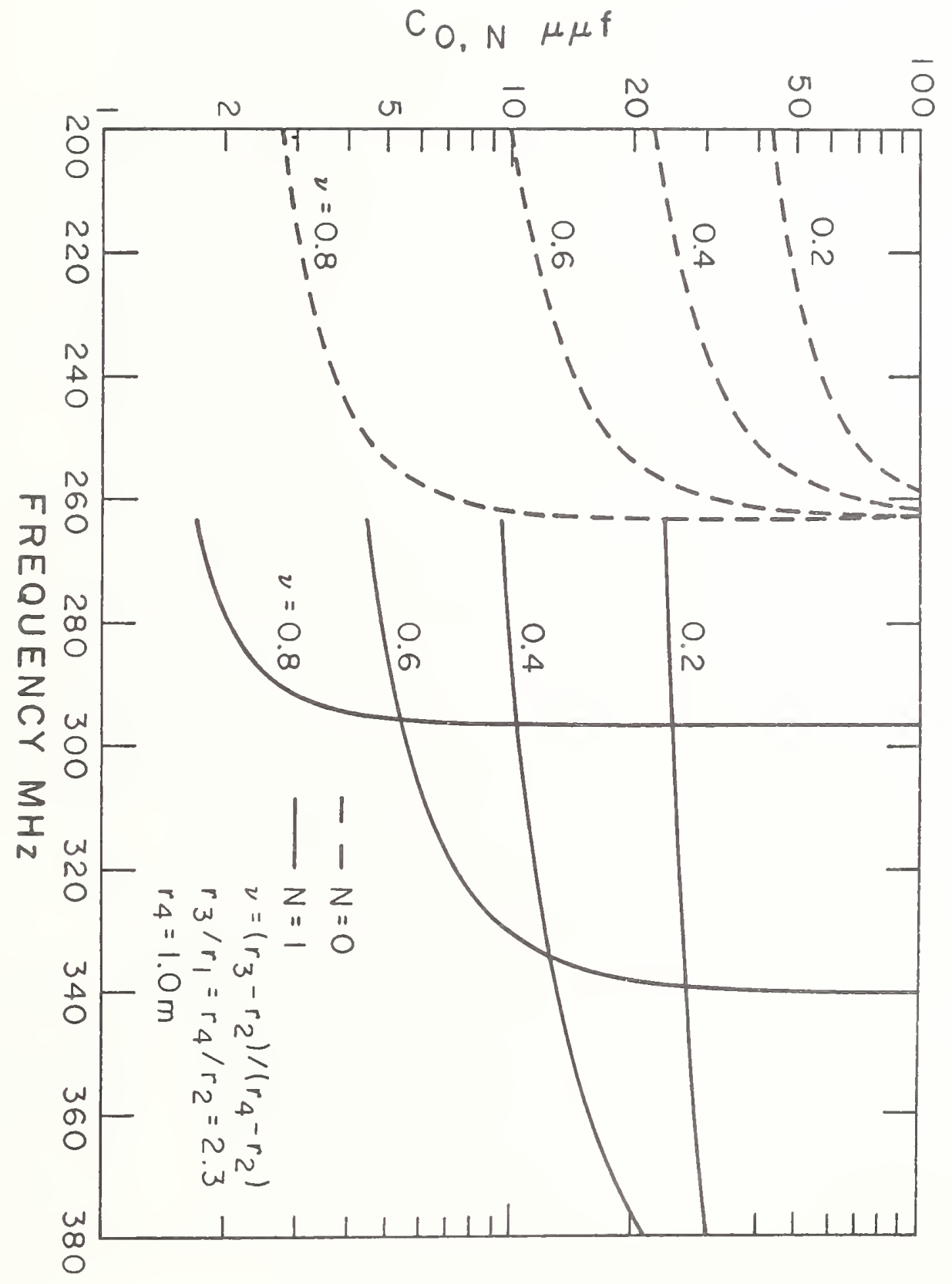

Figure 7a. $\mathrm{C}_{\mathrm{O}, \mathrm{N}}$ vs frequency characteristics of a step discontinuity in a coaxial line 


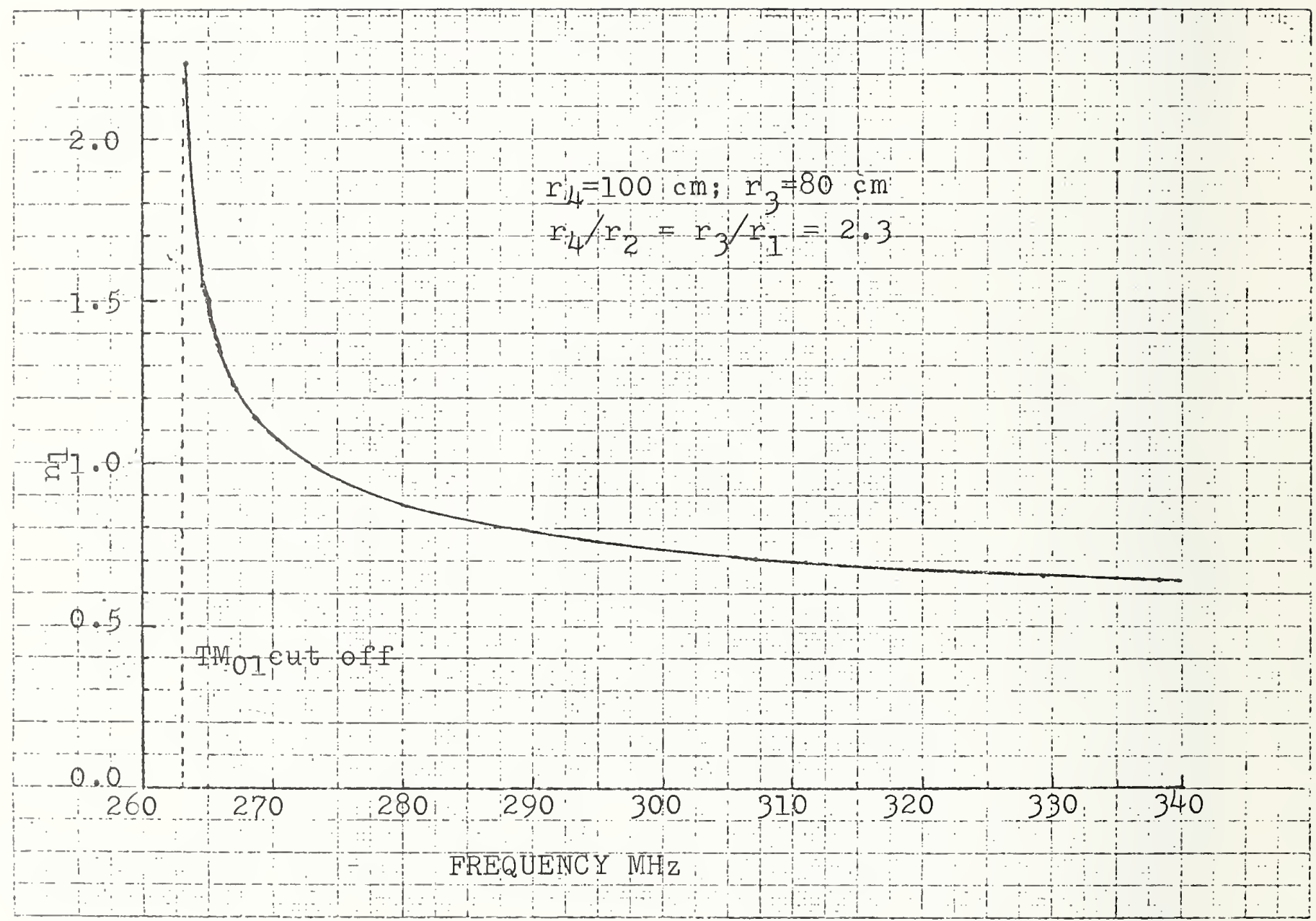

Figure 7b. $n_{1}$ vs frequency characteristics of a step discontinuity in a coaxia' line 


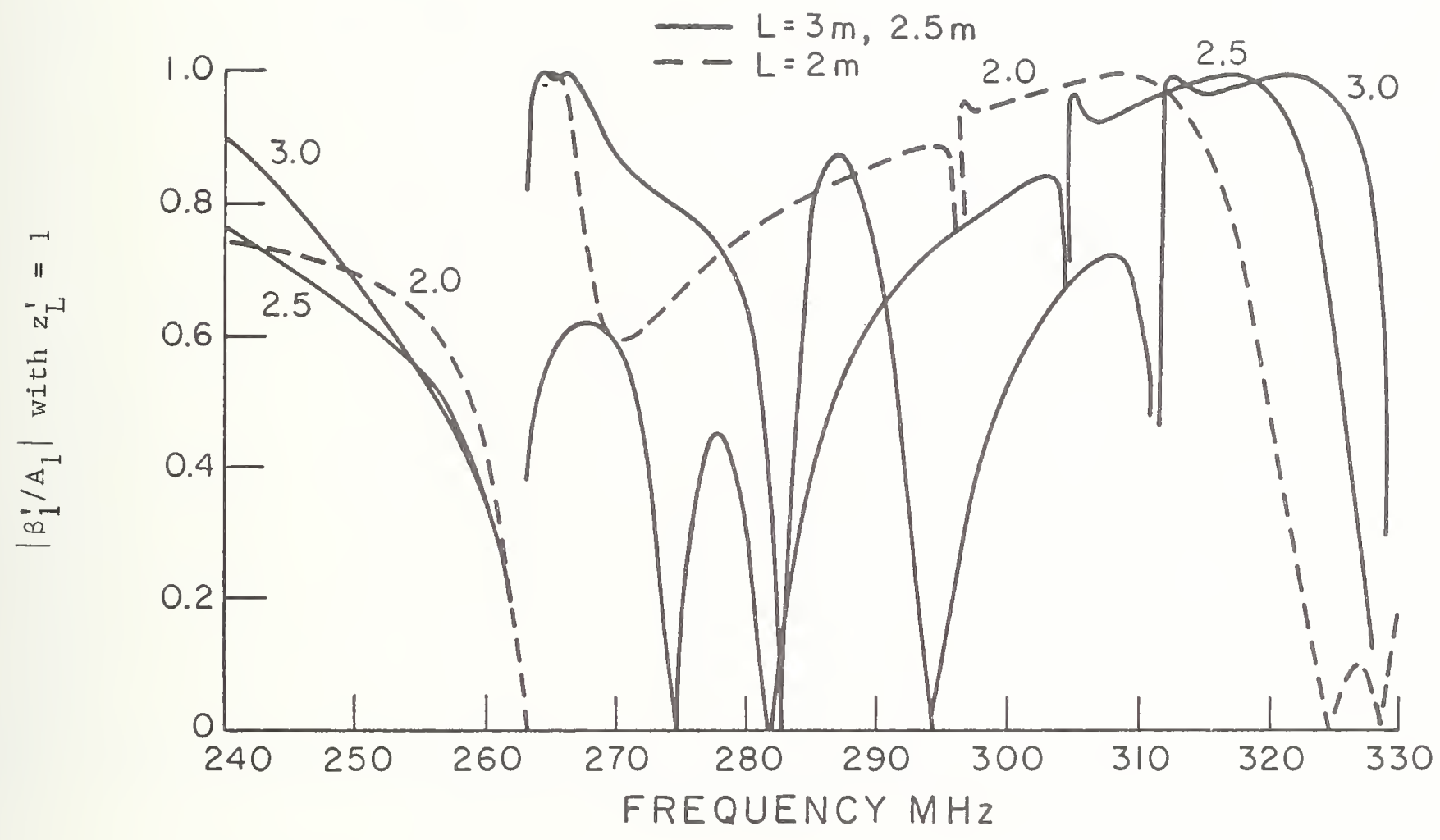

Figure 8. Transmission coefficient vs frequency characteristics of an empty coaxial TEM cell 


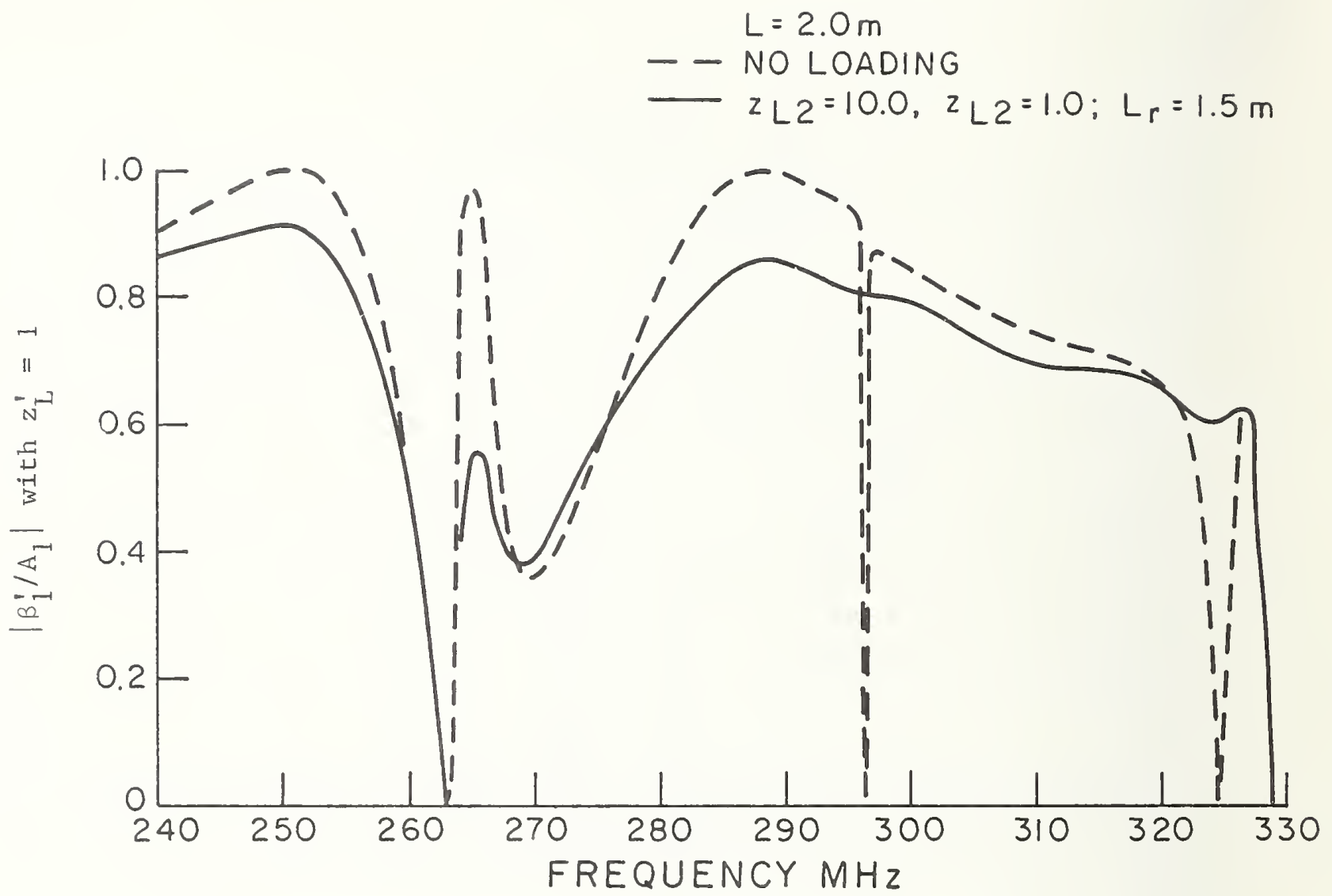

Figure 9. Transmission coefficient vs frequency characteristics of a coaxial TEM cell with internal resistive loading 


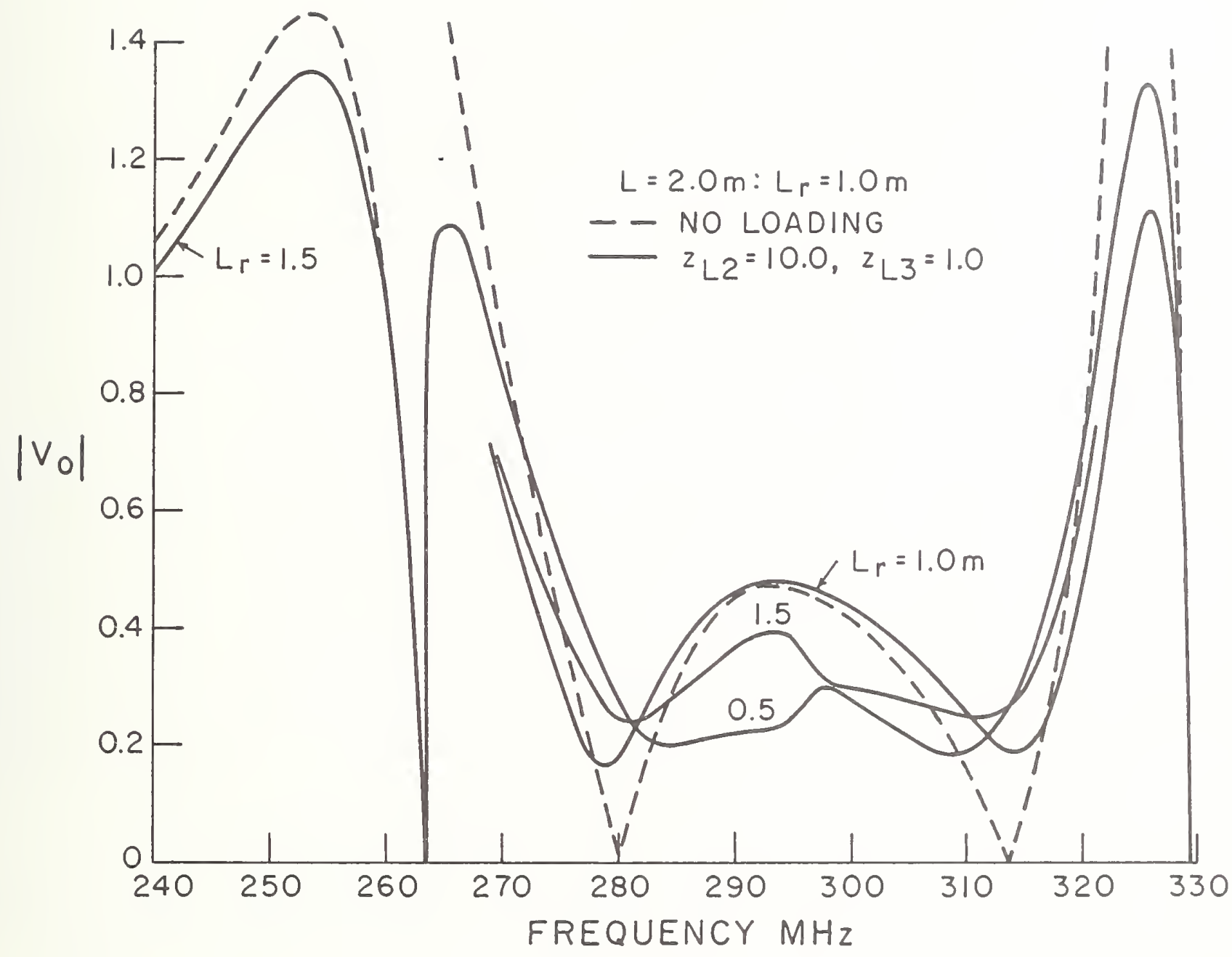

Figure 10. Transmission characteristics of a coaxial TEM cell with an internal source 
One end of the cell is assumed to be terminated with a matched 1 oad $\left(z_{L}=z_{1}\right)$ and the other end with a matched detector $\left(z_{I_{1}}{ }^{\prime}=z_{1}\right)$. The dotted curve shows the results for the cell with just the source and the solid curves show the effect of internal loading. Two resistors with the normalized values $z_{L 2}=10.0$ and $z_{L 3}=1.0$ are assumed to have been connected at a distance $\mathrm{L}_{\mathrm{r}}$ from one end. As expected, the overall insertion loss and the shape of the frequency response is seen to depend on the location of the loading point. However, a drastic improvement in the uniformity of the frequency response seems not possible with such a simple scheme. We should note that in the actual design of the TEM cell with rectangular crosssections, the transition region is usually tapered smoothly from a standard coaxial line. Consequently, it should yield smaller intercoupling between modes than the step discontinuity we studied here. Even so, the deep nulls, particularly the one when TM is near cutoff, appears to be inevitable as confirmed by the experimental 01 measurement [8].

\section{CONCLUSIONS}

In this report we have obtained the scattering matrix of a step discontinuity in a coaxial transmission line where one section of the line is large enough to support $\mathrm{TM}_{01}$ mode. Because of their variational nature, the expressions for the scattering coefficients are expected to be accurate over a wide range of discontinuities. When this is not true, more accurate results can be obtained by substituting an appropriate series for the field distribution in the exact equations $(2.19 \mathrm{a}$ and $\mathrm{b})$. We have extended the concept in a straightforward manner to the more general case where arbitrary numbers of modes are assumed to be propagating in either section of the line, and presented simple expressions for the parameters of the equivalent circuit which can be used to obtain the scattering matrix in any frequency range. 
Since the scattering matrix is characteristic of the junction itself, i.e., independent of the external connections to the ports, one can use the same scattering matrix to analyze TEM cells of different lengths through the method presented in Section IV without having to solve the entire problem every time the length is changed. The method can be used to analyze coaxial structures with a number of step discontinuities spaced at irregular intervals, in any frequency range of interest, with an increasing amount of complexity as the frequency is increased. However, the method by itself is simple and straightforward.

\section{ACKNOWLEDGMENTS}

The authors are very grateful to Drs. M. T. Ma and M. Kanda for their technical discussions and helpful suggestions during the course of this work. The cooperation and assistance received from M. Crawford is also acknowledged. The work reported herein would not have been possible without the constant support and encouragement from C. K. S. Miller and F. X. Ries.

\section{REFERENCES}

[1] J.W. Adams, "Electromagnetic interference measurement program at the National Bureau of Standards, USNC/URSI, Commissions I-VIII, annual meeting, p. 33, Oct. 20-23, 1975.

[2] M.L. Crawford, "Generation of standard EM field using TEM transmission cells," IEEE Trans. on Electromagn. Compat., Vol. EMC-16, No. 4, pp. 189-195, Nov. 1974 .

[3] J.C. Tippet and D.C. Chang, "Radiation characteristics of dipole sources located inside a rectangular, coaxial transmission 1ine," National Bureau of Standards Internal Report, NBSIR 75-829, January 1976. 
[4] J.C. Tippet, D.C. Chang and M.L. Crawford, "An analytical and experimental determination of the cutoff frequencies of higher order TE modes in a TEM cell," National Bureau of Standards Internal Report, NBSIR 76-841, June 1976.

[5] J.C. Tippet and D.C. Chang, "Higher order modes in rectangular coaxial line with infinitely thin inner conductor," National Bureau of Standards Internal Report, NBSIR 78-873, March 1978.

[6] R.N. Ghose, Microwave Circuit Theory and Analysis, New York: McGraw-Hill Book Company, Inc., 1963.

[7] N. Marcuvitz, Waveguide Handbook, Vol. 10 of M.I.T. Rad. Lab. Series, New York: McGraw-Hil1 Book Company, Inc., 1951.

[8] M.L. Crawford, J.L. Workman, and C.L. Thomas, "Expanding the bandwidth of TEM cells for EMC measurements," IEEE Trans. on Electromagn. Compat., Vo1. EMC-20, No. 3, pp. 368-375, Aug. 1978. 
Expression for the scattered magnetic field

The total magnetic field in Region $\mathrm{A}(\mathrm{z} \leq 0), \mathrm{H}_{\phi \mathrm{A}}$ satisfies the differential equation

$$
\left\{\frac{\partial^{2}}{\partial \rho^{2}}+\frac{1}{\rho} \frac{\partial}{\partial \rho}-\frac{1}{\rho}+\frac{\partial^{2}}{\partial z^{2}}+\beta_{0, A}^{2}\right\} H_{\phi A}(\rho, z)=0
$$

and the boundary condition

$$
\frac{1}{\rho} \frac{\partial}{\partial \rho}\left(\rho \mathrm{H}_{\phi \mathrm{A}}\right)=0 \quad \text { for } \rho=\mathrm{r}_{1} \text { and } \mathrm{r}_{3}
$$

The scattered magnetic field in the same region, ${ }_{11}^{S}(\rho, z)$ is given by

$$
\mathrm{H}_{\dot{\phi} \mathrm{A}}^{\mathrm{S}}(\rho, z)=\mathrm{H}_{\phi A}(\rho, z)-\mathrm{H}_{\phi 1}^{+}(\rho, z)
$$

Since the incident field $\mathrm{H}_{\phi 1}^{+}$satisfies (Al.la and b), the scattered field should also satisfy the same equations and the radiation condition

$$
\left(\frac{\partial}{\partial z}-i \beta_{0, A}\right) H_{\phi A}^{S}(\rho, z) \rightarrow 0 \quad \text { as } z \rightarrow-\infty
$$

Keeping the above requirements in view, we can write the scattered fields as

$$
H_{\phi A}^{S}(\rho, z)=p_{p}^{\infty}=0 C_{p} z_{p}\left(r_{1}, r_{3} ; \rho\right) e^{i \beta} p, A^{z}
$$

where the orthonormal functions $Z_{p}$ and the constants $B_{p}, A$ have been defined in Section II. In view of the orthonormal property of $z_{p}$, we can easily verify that

$$
C_{p}=\left(i \beta_{p, A}\right)^{-1} \int_{r_{1}}^{r_{3}} \frac{\partial H_{\phi A}^{s}}{\partial z}\left(\rho^{\prime}, z=0\right) z_{p}\left(r_{1}, r_{3} ; \rho^{\prime}\right) \rho^{\prime} d \rho^{\prime}
$$

Further noting that

$$
E_{\phi A}^{S}(\rho, z)=\frac{i}{\omega \varepsilon} \frac{\partial}{\partial z} H_{\phi A}^{S}(\rho, z)
$$

we can immediately write 


$$
H_{\phi A}^{S}(\rho, z)=-\omega \varepsilon \int_{r_{1}}^{r_{3}} E_{p A}^{S}\left(\rho^{\prime}, 0\right) \rho^{\prime} d \rho^{\prime} \sum_{p=0}^{\infty} z_{p}\left(r_{1}, r_{3} ; \rho\right) z_{p}\left(r_{1}, r_{3} ; \rho^{\prime}\right)\left(\beta_{p, A}\right)^{-1} \exp \left(+i \beta p, A^{z}\right)
$$

We can obtain an expression for $H_{\phi B}^{S}$ in a similar manner by noting that $H_{\phi B}^{S}$ should satisfy the following radiation condition

$$
\left(\frac{\partial}{\partial z}+i \beta_{O, B}\right) H_{\phi B}^{S}(\rho, z) \rightarrow 0 \quad \text { as } z \rightarrow+\infty
$$


Variational relations for the scattering parameters

In this appendix we derive the relations (2.19a and b). We use the expansions obtained in Appendix I for the scattered magnetic fields, and, noting that the total fields are given by the sum of the scattered and the incident fields, we write

$$
\begin{aligned}
& H_{\phi A}(\rho, z)=H_{\phi 1}^{+}(\rho, z)-w \varepsilon \int_{r_{1}}^{r_{3}} E_{\rho S^{A}}^{A}\left(\rho^{\prime}, 0\right) \rho^{\prime} d \rho^{\prime} \sum_{p=0}^{\infty} z_{p}\left(r_{1}, r_{3} ; \rho\right) \\
& H_{\phi B}(\rho, z)=H_{\phi 2}^{+}(\rho, z)+H_{\phi 3}^{+}(\rho, z)+w \varepsilon \int_{p}^{r_{1}} E_{\rho S^{B}}^{B}\left(\rho^{\prime}, 0\right) \rho^{\prime} d \rho^{\prime} \sum_{p=0}^{\infty} z_{p}\left(r_{2}, r_{4} ; \rho\right) \\
& E_{\rho A}(\rho, z)=E_{\rho A}^{S}(\rho, z)+E_{\rho 1}^{+}(\rho, z) \\
& E_{\rho B}(\rho, z)=E_{\rho B}^{S}(\rho, z)+E_{\rho 2}^{+}(\rho, z)+E_{\rho 3}^{+}(\rho, z)
\end{aligned}
$$

where the incident magnetic fields $H_{\phi_{i}}^{+}$, for $i=1,2,3$ are given by (2.la-c) and the incident transverse electric fields $\mathrm{E}_{\rho i}^{+}$are related to $\mathrm{H}_{\phi_{i}}^{+}$through relations of the form (A1.6). In view of the equations (2.1a-c) we identify the coefficients $\mathrm{b}_{1}, \mathrm{~b}_{2}, \mathrm{~b}_{3}$ of the propagating reflected fields, in the expressions for $\mathrm{H}_{\phi \mathrm{A}}$ and $\mathrm{H}_{\phi \mathrm{B}}$ to be

$$
\begin{aligned}
& \left.b_{1}=s_{11} a_{1}+s_{12} a_{2}+s_{13} a_{3}=\left(z_{1}\right)^{-1 / 2} \int_{r_{1}}^{r_{3}} E_{\rho A}^{s}(\rho), 0\right) d \rho ! \\
& b_{2}=s_{12} a_{1}+s_{22} a_{2}+s_{23} a_{3}=\left(z_{2}\right)^{-1 / 2} \int_{r_{2}}^{r_{4}} E_{\rho B^{\prime}}^{s}\left(\rho^{\prime}, 0\right) d_{\rho}^{\prime} \\
& b_{3}=s_{13} a_{1}+s_{23} a_{2}+s_{33^{2}} a_{3}=\left(\frac{2 \pi \beta_{o, B}}{\zeta_{0} \beta_{1, B}}\right)^{1 / 2} \int_{r_{2}}^{r_{4}} E_{\rho B^{s}}^{s}\left(\rho^{\prime}, 0\right) z_{1}\left(r_{2}, r_{4} ; \rho^{\prime}\right) \rho^{\prime} d_{\rho^{\prime}}
\end{aligned}
$$


where

$$
z_{1}=\left(\zeta_{0} / 2 \pi\right) \ln \left(r_{3} / r_{1}\right)
$$

Using ( $\mathrm{A} 2.2 \mathrm{a}$ and $\mathrm{b})$, we can write

$$
\begin{aligned}
& \int_{r_{1}}^{r_{3}} E_{\rho A}^{S}\left(\rho^{\prime}, 0\right) d \rho^{\prime}=\int_{r_{2}}^{r_{3}} E_{\rho}\left(\rho^{\prime}, 0\right) d \rho^{\prime}-a_{1} \sqrt{z_{1}}
\end{aligned}
$$

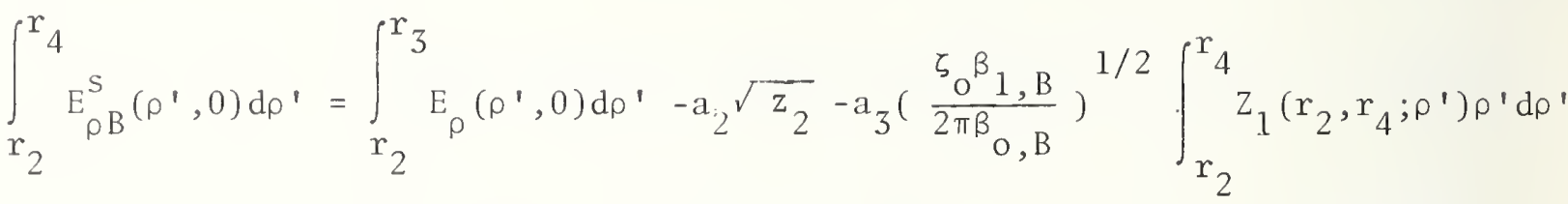

where

$$
E_{\rho A}(\rho, 0)=E_{\rho B}(\rho, 0)=E_{\rho}(\rho, 0)
$$

and we used the boundary condition

$$
\mathrm{E}_{\rho}(\rho, 0)=0 \text { for } \mathrm{r}_{1}<\rho<\mathrm{r}_{2} \text { and } \mathrm{r}_{3}<\rho<\mathrm{r}_{4}
$$

To obtain a variational relation involving $\mathrm{S}_{11}, \mathrm{~S}_{12}$, and $\mathrm{S}_{22}$ we consider the case when $a_{1}=a_{2}=1$ and $a_{3}=0$ and denoting the field quantities corresponding to this case with " " on top, we write

$$
\begin{aligned}
& \tilde{H}_{\phi A}(\rho, z)=\left(2 \pi \zeta_{0}\right)^{-1 / 2} z_{0}\left(r_{1}, r_{3} ; \rho\right) e^{-i \beta} 0, A^{z}-\left(S_{11}+S_{12}\right)\left(2 \pi \zeta_{0}\right)^{-1 / 2} \\
& z_{0}\left(r_{1}, r_{3} ; \rho\right) e^{+i \beta} o, A^{z}-w \varepsilon \int_{r_{1}}^{r_{3}} \tilde{E}_{\rho A^{s}}^{s}\left(\rho^{\prime}, 0\right) \rho^{\prime} d \rho^{\prime} p^{\infty}=1 \\
& z_{p}\left(r_{1}, r_{3} ; \rho\right) z_{p}\left(r_{1}, r_{3} ; \rho^{\prime}\right)\left(\beta_{p, A}\right)^{-1} \exp \left(+i \beta_{p, A} z\right) \\
& H_{\phi B}(\rho, z)=-\left(2 \pi \zeta_{0}\right)^{-1 / 2} z_{0}\left(r_{4}, r_{4} ; \rho\right) e^{+i \beta} 0, B^{z}+\left(S_{12}+S_{22}\right)\left(2 \pi \zeta_{0}\right)^{-1 / 2} z_{0}\left(r_{2}, r_{4} ; \rho\right) \\
& e^{-i \beta} \rho, B^{z}+w \varepsilon \int_{r_{2}}^{r^{4}} \tilde{E}_{\rho B}^{s}\left(\rho^{\prime}, 0\right) \rho^{\prime} d \rho^{\prime} \sum_{p=1}^{\infty} z_{p}\left(r_{2}, r_{4} ; \rho\right) z_{p}\left(r_{2}, r_{4} ; \rho^{\prime}\right) \\
& \left(\beta_{p, B}\right)^{-1} \exp \left(-i \beta_{p, B}{ }^{z}\right)
\end{aligned}
$$


Using the orthogonal property of $Z_{p}$ and (A2.5) we can establish the following relations:

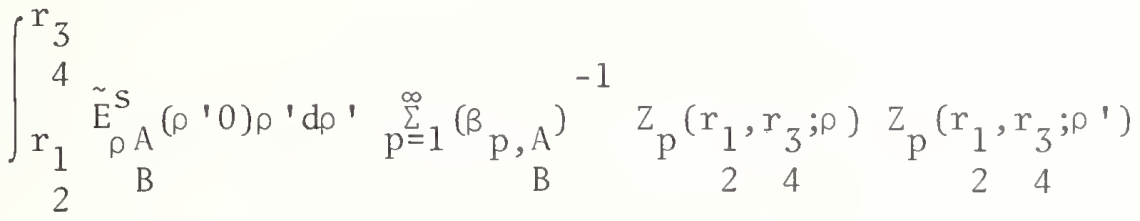

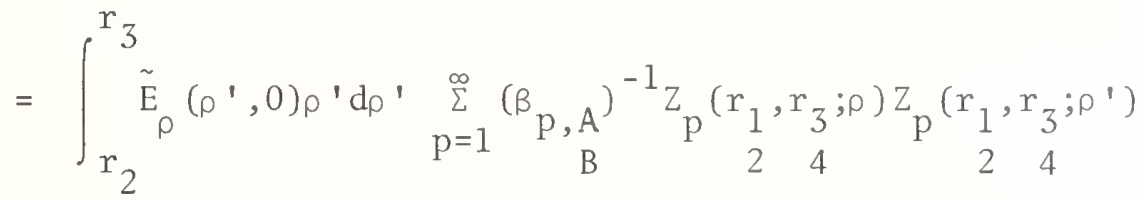

where $\tilde{\mathrm{E}}_{\rho}(\rho, 0)$ is the total transverse electric field at the junction for the case when $a_{1}=a_{2}=1$ and $a_{3}=0$.

Enforcing the continuity of the total tangential magnetic field across the boundary, that is,

$$
\tilde{\mathrm{H}}_{\phi \mathrm{A}}(\rho, 0)=\tilde{\mathrm{H}}_{\phi \mathrm{B}}(\rho, 0)
$$

and making use of (A2.7), we obtain

$$
\begin{aligned}
& \left\{\left(1-\mathrm{S}_{11}-\mathrm{S}_{12}\right)+\mathrm{n}_{\mathrm{o}}\left(1-\mathrm{S}_{12}-\mathrm{S}_{22}\right)\right\} \mathrm{Z}_{\mathrm{o}}\left(\mathrm{r}_{1}, \mathrm{r}_{3} ; \rho\right) \\
& =\left(2 \pi \zeta_{0}\right)^{1 /-}(\omega \varepsilon)\left\{\int _ { r _ { 2 } } ^ { r _ { 3 } } E _ { \rho } ( \rho ^ { \prime } , 0 ) \rho ^ { \prime } d \rho ^ { \prime } \left[\sum_{p=1}^{\infty} z_{p}\left(r_{1}, r_{3} ; \rho\right) z_{p}\left(r_{1}, r_{3} ; \rho^{\prime}\right)\left(B_{p, A}\right)^{-1}\right.\right. \\
& \left.\left.+\sum_{p=1}^{\infty} z_{p}\left(r_{2}, r_{4} ; \rho\right) z_{p}\left(r_{2}, r_{4} ; \rho^{\prime}\right)\left(\beta_{p, B}\right)^{-1}\right]^{\prime}\right\}
\end{aligned}
$$

Multiplying (A2.9) by $\tilde{\mathrm{E}}_{\rho}(\rho, 0) \rho \mathrm{d} \rho$ and integrating between the 1 imits $\mathrm{r}_{2}$ and $\mathrm{r}_{3}$, we obtain

$$
\begin{aligned}
& \left\{\left(1-S_{11}-S_{12}\right)+n_{0}\left(1-S_{12}-S_{22}\right)\right\} \int_{r_{2}}^{r_{\tilde{E}}}(\rho, 0) d \rho \\
& =\left(\ln \frac{r_{3}}{r_{1}}\right)\left(\beta_{0, A} / \sqrt{z_{1}}\right)\left\{\sum_{p=1}^{\infty}\left(\beta_{p, A}\right)^{-1}\left(\int_{r_{2}}^{r_{p}} z_{p}\left(r_{1}, r_{3} ; \rho\right) \tilde{E}_{\rho}(\rho, 0) \rho d \rho\right)^{2}\right. \\
& \left.+\sum_{q=1}^{\infty}\left(\beta_{p, B}\right)^{-1}\left(\int_{r_{2}}^{r_{3}} z_{p}\left(r_{2}, r_{4} ; \rho\right) \tilde{E}_{\rho}(\rho, 0) \rho d \rho\right)\right\}
\end{aligned}
$$


Further, from (A2.3a) and (A2.4a), we can establish the relation

$$
\left(1+S_{11}+S_{12}\right)=\left(1 / \sqrt{z_{1}}\right) \int_{r_{2}}^{r_{3}} \tilde{E}_{\rho}(\rho, 0) d \rho
$$

Combining the last two equations, and using (2.15a and b), we can immediately obtain (2.19a).

To obtain (2.19b) we repeat a similar procedure with $\mathrm{a}_{1}=\left(1-\mathrm{S}_{33}\right) / \mathrm{S}_{13}, \mathrm{a}_{2}=0$, and $a_{3}=1$ with the modification that we isolate the term containing $z_{1}\left(r_{2}, r_{3} ; \rho\right)$ in the expression for the total magnetic field in region $\mathrm{B}(\mathrm{z} \geq 0)$. 
Proof that the expressions (2.19a and b) are variational.

To verify that the expression (2.19a) for $\left\{2 n_{0}-\left(1+n_{0}^{2}\right) S_{12}\right\} / S_{12}$ is variational in $\tilde{\mathrm{E}}_{\rho}$ we need to prove that a small variation in $\tilde{\mathrm{E}}_{\rho}$ about its true value causes no change in $\left\{2 n_{0}-\left(1+n_{0}^{2}\right) S_{12}\right\} / S_{12}$.

Let

$$
y_{1}=\left\{2 n_{0}-\left(1+n_{0}^{2}\right) S_{12}\right\} /\left\{\rho \ln \left(r_{3} / r_{1}\right) S_{12}\right\}
$$

From $(2.19 \mathrm{a})$

$$
\begin{aligned}
& y_{1}\left(\int_{r_{2}}^{r_{\tilde{n}}} \tilde{E}_{\rho}(\rho, 0) d \rho\right)^{2}=\sum_{p=1}^{\infty}\left(\int_{r_{2}}^{r_{3}} \tilde{E}_{\rho}(\rho, 0) z_{p}\left(r_{1}, r_{3} ; \rho\right) \rho d \rho\right)^{2} / B p, A \\
& +\sum_{\mathrm{p}=1}^{\infty}\left(\int_{\mathrm{r}_{2}}^{\mathrm{r}_{3}} \tilde{\mathrm{E}}_{\rho}(\rho, 0) \mathrm{z}_{\mathrm{p}}\left(\mathrm{r}_{2}, \mathrm{r}_{4} ; \rho\right) \rho \mathrm{d} \rho\right)^{2} / \mathrm{B}_{\mathrm{p}, \mathrm{B}}
\end{aligned}
$$

Small variations in $y_{1}$ and $\tilde{\mathrm{E}}_{\rho}$ give

$$
\begin{aligned}
& \Delta y_{1}\left(\int_{r_{2}}^{r_{3}} \tilde{E}_{\rho}(\rho, 0) d \rho\right)^{2}+2 y_{1} \int_{r_{2}}^{z_{\tilde{E}}}(\rho, 0) d \rho \int_{r_{2}}^{r_{2}} \Delta \tilde{E}_{\rho}(\rho, 0) d \rho \\
& =2 \sum_{p=1}^{\infty}\left(\int_{r_{2}}^{r_{2}} \tilde{E}_{\rho}(\rho, 0) z_{p}\left(r_{1}, r_{3} ; \rho\right) \rho d \rho\right)\left(\int_{\Delta \tilde{E}_{\rho}}^{r_{3}}(\rho, 0) z_{p}\left(r_{1}, r_{3} ; \rho\right) \rho d \rho\right) \\
& +2 \sum_{p=1}^{\infty}\left(\int_{r_{2}}^{r_{3}} \tilde{E}_{\rho}(\rho, 0) z_{p}\left(r_{2}, r_{4} ; \rho\right) \rho d \rho\right)\left(\int_{r_{2}}^{r_{3}} \tilde{E}_{\rho}(\rho, 0) z_{p}\left(r_{2}, r_{4} ; \rho\right) \rho d \rho\right)
\end{aligned}
$$

From (A2.11) and (2.15a) we can verify that

$$
\mathrm{S}_{12}=\left(\frac{\mathrm{n}_{\mathrm{o}}}{1+\mathrm{n}_{\mathrm{o}}}\right)\left(\mathrm{z}_{1}\right)^{-1 / 2} \int_{\mathrm{r}_{2}}^{\mathrm{r}_{3}} \tilde{\mathrm{E}}_{\rho}(\rho, 0) \mathrm{d} \rho
$$

Multipliying (A2.9) by $\Delta \tilde{E}_{\rho}(\rho, 0) \rho d_{\rho}$ and integrating between the limits $r_{2}$ and $r_{3}$ we obtain, after using (2.15a and b), 


$$
\begin{aligned}
& \left\{2 n_{0}-\left(1+n_{0}^{2}\right) S_{12}\right\} \int_{r_{2}}^{r_{3}} \Delta \tilde{E}_{\rho}(\rho, 0) d \rho=\left(\frac{n_{0}}{1+n_{0}}\right)\left(2 \pi \zeta_{0} \ln \frac{r_{3}}{r_{1}}\right)^{1 / 2}(\omega \varepsilon) \\
& \left\{\sum_{p=1}^{\infty}\left(\int_{r_{2}}^{r_{3}} \tilde{E}_{\rho}\left(\rho^{\prime}, 0\right) z_{p}\left(r_{1}, r_{3} ; \rho^{\prime}\right) \rho^{\prime} d \rho^{\prime}\right)\left(\int_{r_{2}}^{r_{3}} \Delta \tilde{E}_{\rho}(\rho, 0) z_{p}\left(r_{1}, r_{3} ; \rho\right) \rho d \rho\right) / \beta_{p}, A\right. \\
& \left.+\sum_{p=1}^{\infty}\left(\int_{r_{2}}^{r_{2}}\left(\rho^{\prime}, 0\right) z_{p}\left(r_{2}, r_{4} ; \rho^{\prime}\right) \rho^{\prime} d \rho^{\prime}\right)\left(\int_{3}^{r_{3}} \Delta \tilde{E}_{\rho}(\rho ; 0) z_{p}\left(r_{2}, r_{4} ; \rho\right) \rho d \rho\right) / \beta p, B\right\}
\end{aligned}
$$

Using (A3.1), (A3.4), and (A3.5), we can immediately verify that the term

$$
2 y_{1} \int_{\mathrm{r}_{2}}^{\mathrm{r}_{3}} \tilde{\mathrm{E}}_{\rho}(\rho, 0) \mathrm{d} \rho \int_{\mathrm{r}_{2}}^{\mathrm{r}_{3}} \Delta \tilde{\mathrm{E}}_{\rho}(\rho, 0) \mathrm{d} \rho
$$

is identical to the expression on the right-hand side of (A3.3), which implies that

$$
\Delta y_{1}\left(\int_{r_{2}}^{r_{3}} \tilde{E}_{\rho}(\rho, 0) d \rho\right)^{2}=0
$$

which establishes the variational nature of the expression given in (2.19a). Proceeding in a similar manner, we can prove that $(2.19 b)$ is also variational in $\tilde{\tilde{E}}_{\rho}$ 
Relations characterizing the transmission properties of the TEM cell.

Denoting the incident and the reflected voltage amplitudes at different points along the cell as indicated in Fig. 3, we recognize the following relations:

$$
\begin{aligned}
& \tilde{A}_{2}=V_{2} e^{-i \beta_{0}\left(L_{r}-L_{S}\right)}+B_{2} e^{-i \beta_{0} L_{r}}
\end{aligned}
$$

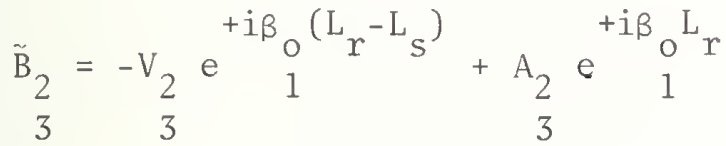

where

$$
\begin{aligned}
& \beta_{0}=\beta_{0, A}=\beta_{0, B}=\omega / c \\
& \beta_{I}=\beta_{1, A}
\end{aligned}
$$
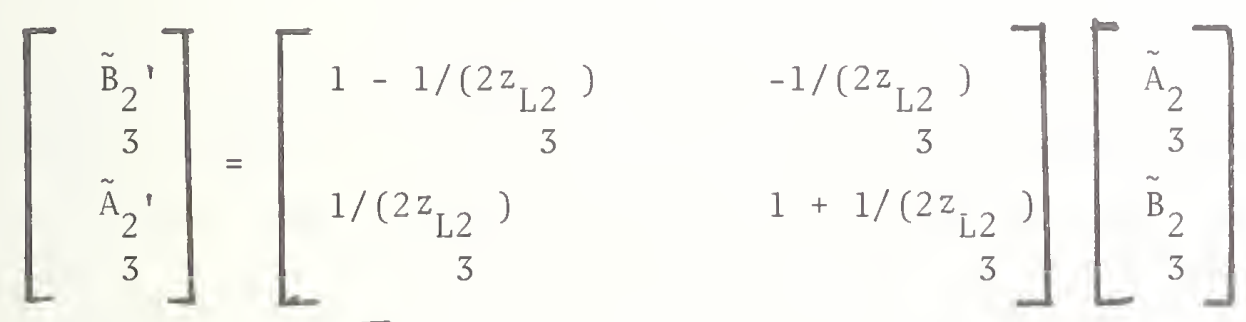

$$
\begin{aligned}
& {\left[\begin{array}{c}
A_{2}^{\prime} \\
3 \\
B_{2}^{\prime} \\
3
\end{array}\right]=\left[\begin{array}{ccc}
e^{-i \beta} \mathrm{o}_{r}^{\prime} & 0 \\
1 & e^{+i \beta} \mathrm{o}_{\mathrm{r}}^{\prime} \\
0 & 1
\end{array}\right]\left[\begin{array}{c}
\tilde{B}_{2}^{\prime} \\
3 \\
\tilde{\mathrm{A}}_{2}^{\prime} \\
3
\end{array}\right]} \\
& A_{1}=v_{1} /\left(1+z_{L}\right)+B_{1}\left(z_{L}-1\right) /\left(z_{L}+1\right) \\
& A_{1}^{\prime}=V_{1}^{\prime} /\left(1+z_{L}^{\prime}\right)+B_{1}^{\prime}\left(z_{L}^{\prime}-1\right) /\left(z_{L}^{\prime}+1\right)
\end{aligned}
$$

Combining (A4.1) - (A4.4) we obtain the following relations:

$$
\begin{aligned}
& A_{2}^{\prime}=B_{2} T_{2}(1,1) e^{-i \beta_{0} L}+A_{2} T_{2}(1,2) e^{i \beta_{0}\left(L_{r}-L_{r}{ }^{\prime}\right)} \\
& \begin{array}{llll}
3 & 3 & 3 & 3
\end{array}
\end{aligned}
$$

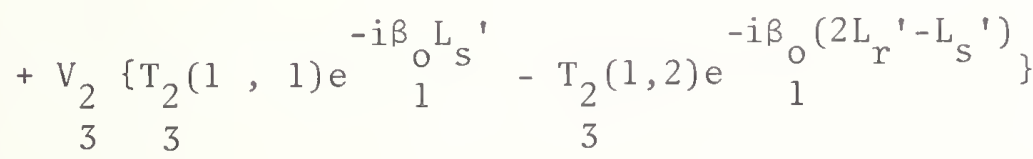




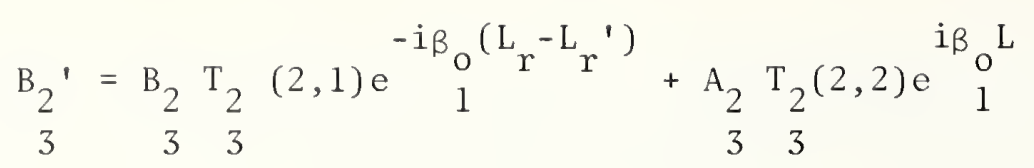

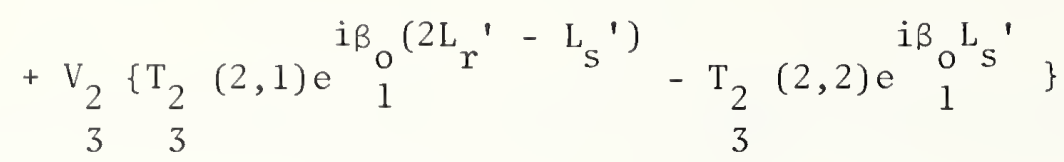

where

$$
\begin{aligned}
& \mathrm{T}_{2}(1,1)=1-1 /\left(2 \mathrm{z}_{\mathrm{L} 2}\right) \\
& 3 \\
& 3 \\
& \mathrm{~T}_{2} \\
& 3 \\
& \mathrm{~T}_{2} \\
& 3
\end{aligned}(1,2)=-\mathrm{T}_{2}(2,1)=-1 /\left(2 \mathrm{z}_{\mathrm{L} 2}\right)
$$

Equations (A4.5a) and (A4.7) may be cast into the following matrix equation:

$$
\left[\begin{array}{lll}
A_{1} & A_{2} & A_{3}
\end{array}\right]^{T}=\bar{A}=\bar{R} \bar{B}+\bar{T} \bar{B}^{\prime}+\bar{V}
$$

where

$$
\begin{aligned}
& \overline{\mathrm{B}}=\left[\begin{array}{lll}
\mathrm{B}_{1} & \mathrm{~B}_{2} & \mathrm{~B}_{3}
\end{array}\right]^{\mathrm{T}} \\
& \overline{\mathrm{B}}^{\prime}=\left[\begin{array}{llll}
\mathrm{B}_{1}^{\prime} & \mathrm{B}_{2}^{\prime} & \mathrm{B}_{3}^{\prime}
\end{array}\right]^{\mathrm{T}}
\end{aligned}
$$

$$
\bar{R}=\left[\begin{array}{c}
\mathrm{R}_{\mathrm{c}} \\
0 \\
0
\end{array}\right.
$$$$
\left.\begin{array}{c}
0 \\
0 \\
R_{c 3} e^{-i 2 \beta} L_{r}
\end{array}\right]
$$

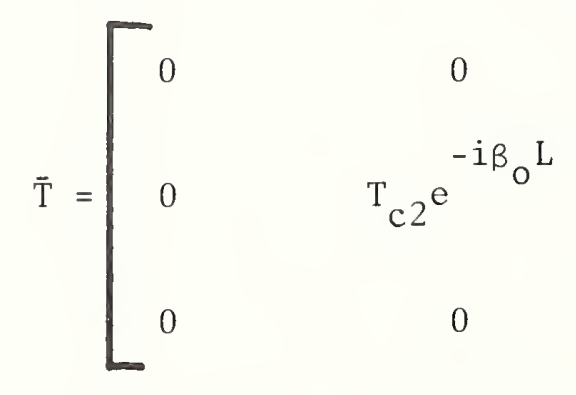

$$
\begin{gathered}
R_{c 2} e^{-i 2 \beta_{0} L_{r}} \\
0
\end{gathered}
$$

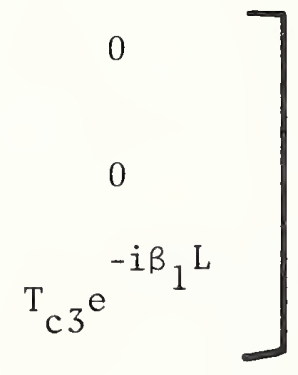

$$
\begin{aligned}
& \overline{\mathrm{V}}=\left[\begin{array}{lll}
\tilde{V}_{1} & \tilde{\mathrm{V}}_{2} & \tilde{\mathrm{V}}_{3}
\end{array}\right]^{\mathrm{T}} \\
& \tilde{V}_{1}=V /\left(1+z_{L}\right) \\
& \tilde{V}_{2}=V_{2}\left\{e^{-i \beta_{o} L_{s}}+R_{c 2} e^{-i \beta_{o}\left(2 L_{r}-L_{s}\right)} 1\right\}
\end{aligned}
$$




$$
\begin{aligned}
& R_{c}=\left(z_{L}-1\right) /\left(z_{L}+1\right) \\
& \mathrm{R}_{\mathrm{c} 2}=-1 /\left(1+2 z_{\mathrm{L} 2}\right) \\
& \mathrm{T}_{\mathrm{c} 2}=2 z_{\mathrm{L} 2} /\left(1+z_{\mathrm{L} 2}\right)
\end{aligned}
$$

Substituting for $A_{2}$ from (A4.7) we can write (A4.6) as

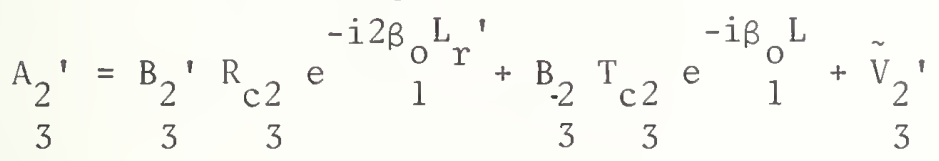

where

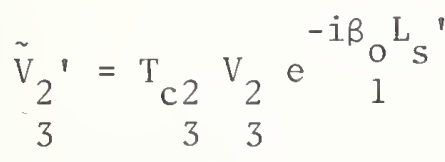

Equations (A4.5b) and (A4.15) may now be put into the following matrix equation:

$$
\left[\mathrm{A}_{1}^{\prime} \mathrm{A}_{2}^{\prime} \mathrm{A}_{3}^{\prime}\right]^{\mathrm{T}}=\overline{\mathrm{A}}^{\prime}=\overline{\mathrm{R}}^{\prime} \overline{\mathrm{B}}^{\prime}+\overline{\mathrm{T}} \overline{\mathrm{B}}+\overline{\mathrm{V}}^{\prime}
$$

where

$$
\begin{aligned}
& \bar{R}^{\prime}=\left[\begin{array}{ccc}
R_{c}{ }^{\prime} & 0 & 0 \\
0 & R_{c 2} e^{-i 2 \beta_{0} L_{r}{ }^{\prime}} & 0 \\
0 & 0 & R_{c 3} e^{-i 2 \beta_{1} L_{r}{ }^{\prime}}
\end{array}\right] \\
& R_{C}^{\prime}=\left(z_{L}^{\prime}-1\right) /\left(z_{L}^{\prime}+1\right) \\
& \bar{V}^{\prime}=\left[\tilde{V}_{1}^{\prime} \tilde{V}_{2}^{\prime} \tilde{V}_{3}^{\prime}\right]^{T} \\
& \tilde{V}_{1}^{\prime}=V^{\prime} /\left(1+z_{L}^{\prime}\right)
\end{aligned}
$$

Noting that

$$
\begin{aligned}
& \bar{B}=S \bar{A} \\
& \bar{B}^{\prime}=S \bar{A}^{\prime}
\end{aligned}
$$

we may write (A4.9) and (A4.17) as

$$
\begin{aligned}
& {[I-\bar{R} S] \bar{A}-\bar{T} S \bar{A}^{\prime}=\bar{V}} \\
& {\left[I-\bar{R}^{\prime} S\right] \bar{A}^{\prime}-\bar{T} S \bar{A}=\bar{V}^{\prime}}
\end{aligned}
$$


whose solution is given by

$$
\begin{aligned}
& \bar{A}=\left[\mathrm{P}_{11} \mathrm{P}_{22}-\mathrm{P}_{12} \mathrm{P}_{21}\right]^{-1}\left[\mathrm{P}_{22} \overline{\mathrm{V}}-\mathrm{P}_{12} \overline{\mathrm{V}}^{\prime}\right] \\
& \overline{\mathrm{A}}^{\prime}=\left[\mathrm{P}_{11} \mathrm{P}_{22}-\mathrm{P}_{21} \mathrm{P}_{12}\right]^{-1}\left[\mathrm{P}_{11} \overline{\mathrm{V}}^{\prime}-\mathrm{P}_{21} \overline{\mathrm{V}}\right]
\end{aligned}
$$

where

$$
\begin{aligned}
& \mathrm{P}_{11}=\mathrm{I}-\overrightarrow{\mathrm{R}} \mathrm{S} \\
& \mathrm{P}_{12}=\mathrm{P}_{21}=-\overline{\mathrm{T}} \mathrm{S} \\
& \mathrm{P}_{22}=\mathrm{I}-\overline{\mathrm{R}} \cdot \mathrm{S}
\end{aligned}
$$


NBS-114A (REV. 0.78)

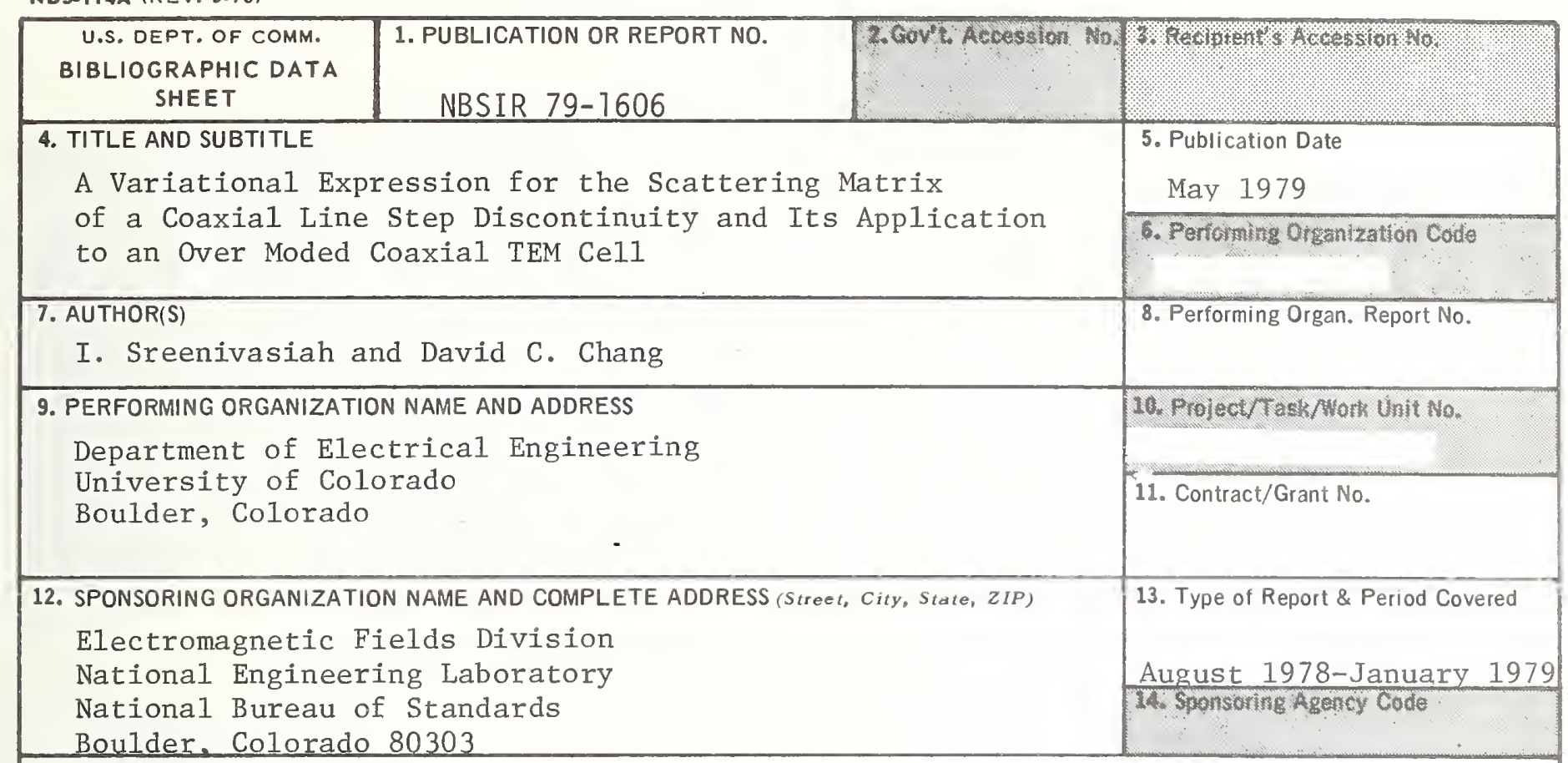

15. SUPPLEMENTARY NOTES

7 Document describes a computer program; SF-185, FIPS Software Summary, is attached.

16. ABSTRACT (A 200-word or less factual summary of most significant information. If document includes a significant bibliography or literature survey, mention it here.)

A step discontinuity in a coaxial transmission 1ine, where one of the sections is large enough to support both TEM and TM 01 modes, may be modeled as a 3-port junction. A variational expression for the (3x3) scattering matrix of such a junction is obtained in simple closed form. The scattering matrix, so obtained, is used to analyze the transmission characteristics of a coaxial TEM cell beyond the cutoff point of the TM 01 mode. Final1y, an equivalent circuit, along with the expressions for the circuit parameters, is given for the general case where the number of propagating modes in each section is finite but arbitrary.

17. KEY WORDS (six to twelve entries; alphabetical order; capitalize only the first letter of the first key word unless a proper name; separated by semicolons)

Coaxial transmission 1ine; cut-off frequency; equivalent circuit; modal analysis; scattering matrix; step discontinuity; TEM-cell; variational formulation.

\begin{tabular}{|c|c|c|}
\hline $\begin{array}{l}\text { 18. AVAILABILITY } \\
\square \text { For Official Distribution. Do Not Release to NTIS }\end{array}$ & $\begin{array}{l}\text { 19. SECURITY CLASS } \\
\text { (THIS REPORT) } \\
\text { UNCLASSIFIED }\end{array}$ & $\begin{array}{l}\text { 21. NO. OF } \\
\text { PRINTED PAGES } \\
\quad 48\end{array}$ \\
\hline $\begin{array}{l}\square \text { Order From Sup. of Doc. U.S. Government Printing Office, Washington, DC } \\
20402, \text { SD Stock No. SNO03-003- } \\
\text { EX Order From National Technical Information Service (NTIS), Springfield, }_{\text {VA. } 22161}\end{array}$ & $\begin{array}{l}\text { 20. SECURITY CLASS } \\
\text { (THIS PAGE) } \\
\text { UNCLASSIFIED }\end{array}$ & $\begin{array}{l}\text { 22. Price } \\
\$ 4.00\end{array}$ \\
\hline
\end{tabular}




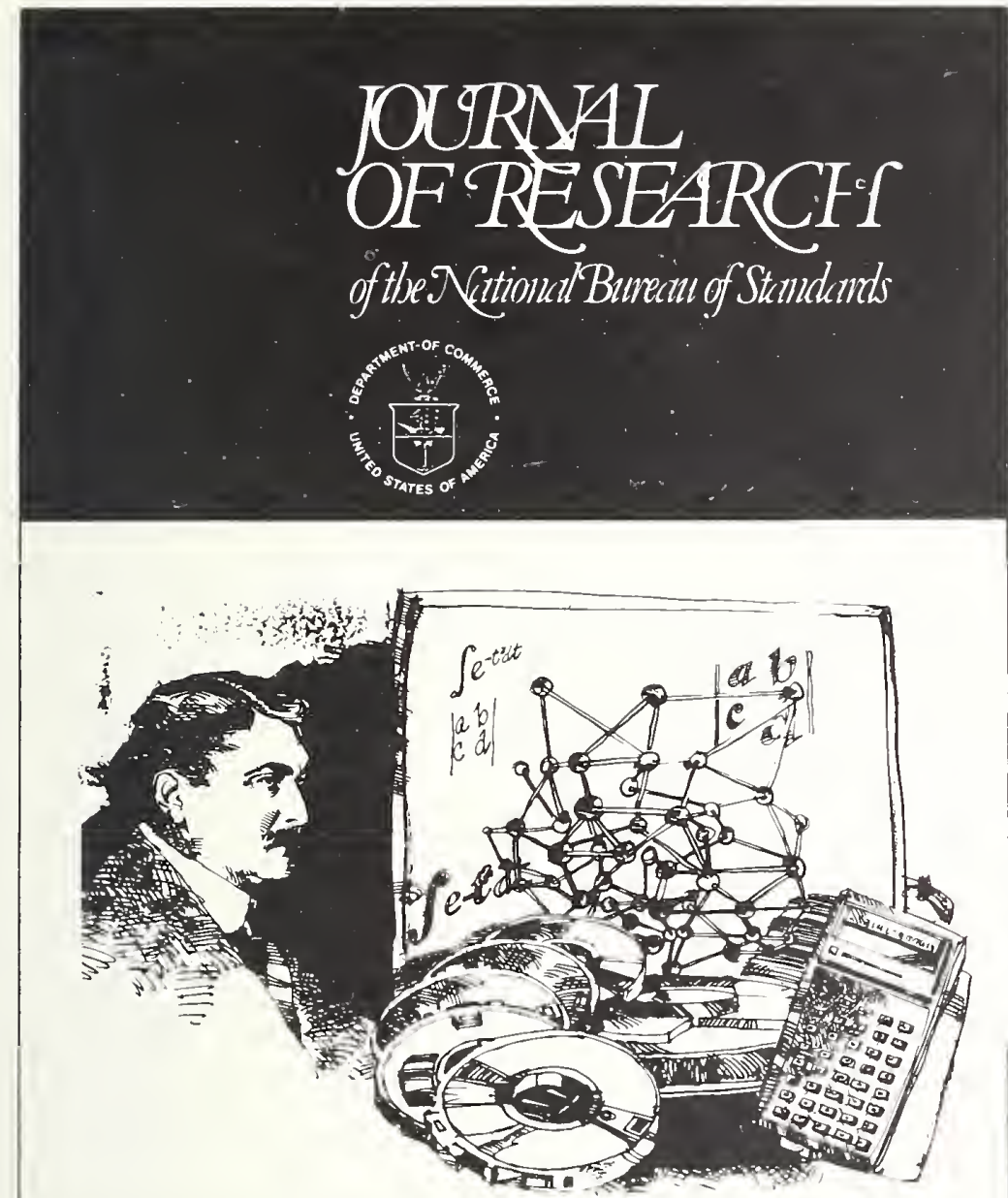

For a review copy, write Journal of

Research, National Bureau of Standards,

U.S. DEPARTMENT OF COMMERCE

Washington, D.C. 20234

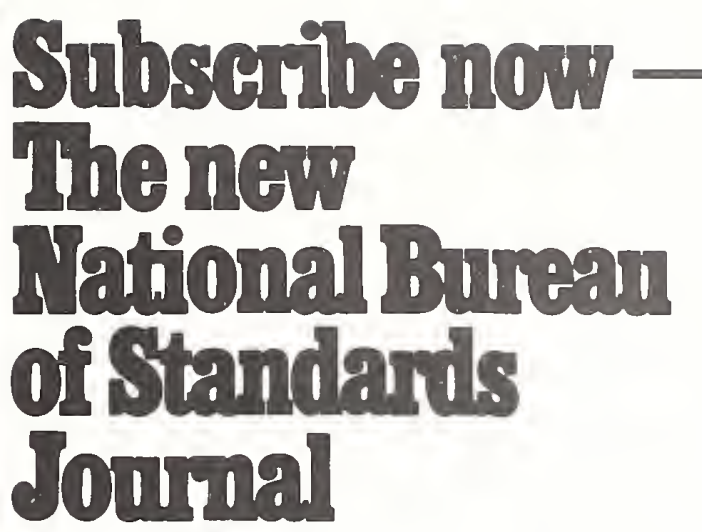

The expanded Journal of Research of the National Bureau of Standards reports NBS research and development in those disciplines of the physical and engineering sciences in which the Bureau is active. These include physics, chemistry, engineering, mathematics, and computer sciences. Papers cover a broad range of subjects, with major emphasis on measurement methodology, and the basic technology underlying standardization. Also included from time to time are survey articles on topics closely related to the Bureau's technical and scientific programs. As a special service to subscribers each issue contains complete citations to all recent NBS publications in NBS and nonNBS media. Issued six times a year. Annual subscription: domestic $\$ 17.00$; foreign $\$ 21.25$. Single copy, $\$ 3.00$ domestic; $\$ 3.75$ foreign.

- Note: The Journal was formerly published in two sections: Section A "Physics and Chemistry" and Section B "Mathematical Sciences."

\section{NBS Board of Editors}

Churchill Eisenhart,

Executive Editor (Mathematics)

John W. Cooper (Physics)

Donald D. Wagman (Chemistry)

Andrew J. Fowell (Engineering)

Joseph O. Harrison (Computer Science)

Stephen J. Smith (Boulder Labs.)
Subscription Order Form

Enter my subscription to NBS Journal of Research

at $\$ 17.00$. Add $\$ 4.25$ for foreign mailing. No additional postage is required for mailing within the United States or its possessions.

(SJR-File Code 2Q)

Send Subscription to:

\section{Name-First, Last}

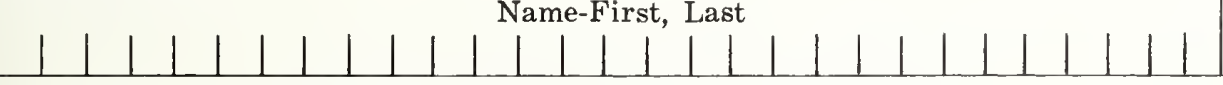

Company Name or Additional Address Line

Street Address

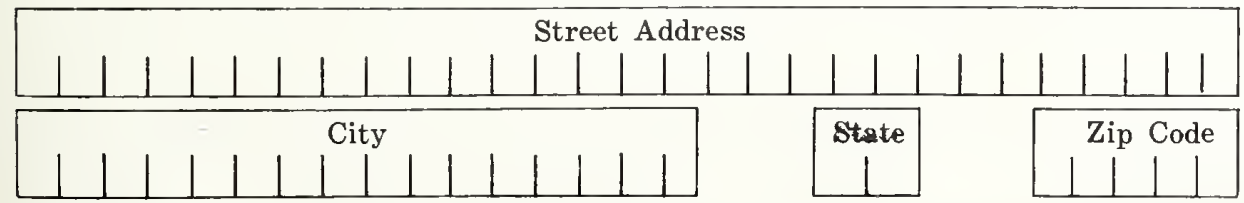

Remittance Enclosed (Make checks payable to Superintendent of Documents)

Charge to my Deposit Account No.
MAIL ORDER FORM TO: Superintendent of Documents Government Printing Office Washington, D.C. 20402 



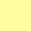


